\title{
Juan Pacheco, privado de Enrique IV, y el oficio de Corregidor de Jerez de La Frontera
}

\author{
Juan Pacheco, favourite of Henry IV, and the Office of Corregidor of Jerez \\ de la Frontera
}

\author{
Alfonso Franco SiLVA \\ Rafael CRUZ MARIÑO \\ Universidad de Cádiz \\ alfonso.franco@uca.es
}

\section{RESUMEN}

Promoción de don Juan Pacheco en el marco de los cambios políticos y ligas nobiliarias de los primeros años del reinado de Enrique IV: marqués de Villena, titular de diversos señoríos, de rentas y mercedes regias, Pacheco es alcaide de Estepona y corregidor perpetuo de Jerez desde 1456. Ejerce el cargo por medio de lugartenientes, rodeándose de una clientela de caballeros jerezanos, y despliega una política inteligente de concordia con linajes nobles poderosos en la zona (Cueva, Guzmán, Ponce de León) hasta que se repliega del escenario político andaluz entre la devolución de la tenencia de Estepona (1460), la toma de Gibraltar (1462) y el comienzo de la revuelta contra Enrique IV (1464).

Palabras clave: Pacheco, Juan. Villena, marqués de. Enrique IV de Castilla. Jerez de la Frontera. Estepona. Gibraltar. Andalucía. Corregidores. Siglo XV.

\begin{abstract}
The promotion of don Juan Pacheco in the framework of the political changes and noble factions that characterized the first years of the reign of Henry IV: marquis of Villena and lord of diverse territories, recipient of royal income and grants, Pacheco was warden of Estepona and perpetual mayor of Jerez from 1456. He exercised his office by means of lieutenants, surrounding himself with a clientele of knights from Jerez, and unfurled an intelligent policy of concord with powerful noble lineages in the area (Cueva, Guzmán, Ponce de León) until the Andalusian political scene receded between the devolution of the tenancy of Estepona (1460), the seizure of Gibraltar (1462), and the beginning of the revolt against Henry IV (1464).
\end{abstract}

Key words: Pacheco, Juan. Villena, marquis of. Henry IV of Castile. Jerez de la Frontera. Estepona. Gibraltar. Andalusia. 15th century.

Sumario: 1. El contexto histórico. 1.1. La paz con Juan de Navarra. 1.2. La guerra contra Granada. 2. El corregimiento de Jerez de la Frontera y le tenencia de Estepona. 2.1. El corregimiento de Jerez: aspectos generales. 2.2. El corregimiento de Juan Pacheco en Jerez de la Frontera. 2.3. La red clientelar del marqués de Villena en la comarca jerezana. 3. El final del corregimiento de Juan Pacheco en el concejo jerezano y el desvanecimiento de su influencia en la región. 4. La tenencia de Estepona: elemento consustancial al corregimiento jerezano. 5. Conclusión. 


\section{EL CONTEXTO HISTÓRICO}

La muerte de Juan II en 1454 y el advenimiento al trono de su hijo Enrique IV, constituyen dos acontecimientos de extraordinaria importancia, no sólo para el futuro del reino de Castilla, sino, sobretodo, para el porvenir del privado del segundo monarca mencionado, el flamante y todopoderoso Juan Pacheco, marqués de Villena. En efecto, tanto él, como su hermano Pedro Girón, el controvertido maestre de Calatrava, recogerán a lo largo del nuevo reinado los frutos de una rica cosecha preparada desde mucho antes. Su protector, el hombre que habían tutelado desde su adolescencia, era ya rey, y ellos se preparaban para gobernar el reino en su nombre, a ser posible solos o, si resultaba necesario, en compañía de algunos nobles, pocos desde luego. Pacheco y Girón alcanzarán, a partir de ahora, la cumbre de su poder y de su fortuna. Uno y otro -el menor hasta su muerte en 1466- serán los máximos protagonistas de todos los grandes y pequeños acontecimientos del nuevo reinado.

Los comienzos del reinado fueron buenos y de gran esperanza frente a la turbulenta época de Juan II. El monarca era joven y parecía fuerte, tenía riquezas acumuladas en su época de príncipe heredero y, sobretodo, buscaba, en palabras del profesor Suárez Fernández, -que sigue siendo, a mi modesto entender, el mejor conocedor de esta época- "edificar la paz sobre el espiritu de la concordia".

En primer lugar, si se quería pacificar el reino, había que llegar a un acuerdo duradero con la liga de nobles, que tantos quebraderos de cabeza había causado a su padre y al condestable Álvaro de Luna, y de la que el nuevo monarca en gran parte se había servido y había utilizado para sus fines en el reinado anterior. ${ }^{2}$ Pero, Enrique IV, aconsejado por su fiel Pacheco, decidió poner en práctica tres medidas. Primero, liberar a todos aquellos que aún se encontraban en prisión. Así se procedería con los condes de Treviño y Alba, y se permitiría también el regreso del almirante don Fadrique, que desde hacía años se hallaba en el destierro. ${ }^{3}$ Segundo, y estrechamente relacionado con lo anterior, conseguir la paz definitiva con el reino de Aragón, de cuyo logro dependía en gran manera la neutralidad de esa nobleza y, sobretodo, terminar de una vez con las pretensiones castellanas de los infantes de ese reino, en especial Juan de Navarra, el único y el más poderoso de los hermanos que quedaban, si exceptuamos desde luego al propio monarca, Alfonso V de Aragón. Las negociaciones para alcanzar un acuerdo en este reino, se iniciarían bien pronto. El resultado como veremos,

${ }^{1}$ SUÁREZ FERNÁNDEZ, Luis: Los Trastámaras de Castilla y Aragón en el siglo XV, en Historia de España. Menéndez Pidal, Tomo XV. Madrid, 1982, p. 220 y Enrique IV de Castilla, Ed. Ariel, Barcelona, 2001, pp. 127-132.

2 Ibídem, p. 221 y Enrique $I V$, p. 130

3 Ibídem y ENRIQUEZ DEL CASTILLO, Diego, Crónica de Enrique IV, Edición de Aureliano SÁNCHEZ MARTÍN, cap. II, pp. 137 y 138, Universidad de Valladolid, 1994. El perdón real para los que hasta entonces habían sido sus enemigos era para este cronista señal evidente de la grandeza de bien y de la magnanimidad del nuevo soberano, y lo expresa así con estas palabras: “¡O syngular excelençia, la virtud del perdón, que donde quiera que mora rroba los coraçones y gana las voluntades para mayor afiçion! ;Bienaventurados los rreynos que de tales rreyes son sufraganos! Ca sy el rrigor de su poderio no se temprase en la mansedumbre del perdón, ni los subditos osarian ser vasallos, ni los que sojuzgan la tierra hallarían quien los seruiese. Asy que la clemençia puebla los rreynos y los haze bevir contentos, la crueldad los desypa y haze ser querellosos". 
sería satisfactorio. Tercero, reanudar la guerra contra el reino nazarí de Granada, no sólo a la búsqueda de prestigio para la Corona, continuando así aquella otra, iniciada a comienzos de los años treinta por su padre y don Álvaro de Luna, que había sido interrumpida de manera inesperada tras la batalla de la Higueruela, sino también, y muy fundamentalmente, para evitar las conspiraciones nobiliarias contra el trono. La guerra contra el musulmán tendría entretenidos a los nobles, y les ofrecería la posibilidad de alcanzar botín y nuevos señoríos a incorporar a sus ya vastos patrimonios.

\subsection{LA PAZ CON JUAN DE NAVARRA}

Neutralizada la Liga nobiliaria, reconciliados con el nuevo monarca los nobles que aún seguían el "partido aragonés", se imponía conseguir la paz con Juan de Navarra. Para el monarca era absolutamente necesaria, a fin de liquidar definitivamente el problema aragonés, que venía condicionando la política interior del reino de Castilla desde la regencia de don Fernando de Antequera. Alejado del reino el jefe del "partido", Juan de Navarra, los nobles que le habían seguido retornarían a la obediencia real, cesando, por consiguiente, las revueltas y tumultos que habían constituido la nota dominante durante el reinado de su padre.

Para su privado, Pacheco, la paz también era necesaria. No hay que olvidar que una gran parte del patrimonio que había conseguido desde el año 1445, formaba parte de los antiguos señoríos de Juan de Navarra. La derrota en Olmedo le había permitido hacerse en ese año y en los siguientes con villas y lugares que desde los últimos años del siglo XIV habían estado sometidos a la jurisdicción de los herederos del infante don Fernando de Antequera. Aunque hubiesen sido derrotados en Olmedo y aunque hubiese ya desaparecido el infante don Enrique, todavía quedaba Juan de Navarra que, a pesar de haber huido al reino de Aragón, podía de nuevo retornar al poder en Castilla por un golpe de fortuna, un cambio en las alianzas, o por cualquier otro procedimiento, y si el éxito le acompañaba podía fácilmente recuperar el patrimonio perdido. A fin de cuentas, situaciones como ésta había conocido ya Pacheco, desde que muchos años atrás entrara como paje al servicio del príncipe heredero. Los vencidos podían ahora volver como vencedores, si la coyuntura cambiaba. Más aún en el caso de Juan de Navarra, que seguía contando en Castilla con partidarios poderosos y con una amplia red de fidelidades y complicidades plenamente activa, que su padre, Fernando de Antequera, había ido tejiendo paulatinamente desde el año 1406 en que accedió a la regencia del reino. ${ }^{4}$ Eran muchos los nobles y caballeros castellanos que debían todo lo que eran a la magnanimidad de don Fernando y a la de sus hijos, los infantes. Había, por tanto, un grupo más o menos numeroso de personajes que, a pesar de que por ahora estaba bastante neutralizado, podía volver a activarse cuando la coyuntura le fuese favorable. Por si fuera poco, Juan de Navarra contaba con el

${ }^{4}$ Sobre algunos personajes encumbrados por el regente don Fernando y más tarde por sus hijos, he escrito algunos trabajos recogidos en mis libros La Fortuna y el Poder, Servicio de Publicaciones de la Universidad de Cádiz, 1996, pp. 241 y ss.; Señores y Señoríos, Servicio de Publicaciones de la Universidad de Jaén, 1997, pp. 95 y ss.; y Grajal de Campos: un señorio leonés en la Baja Edad Media, Servicio de Publicaciones de la Universidad de Cádiz, 2001, pp. 45 y ss. 
apoyo de su hermano el rey de Aragón, Alfonso V, que en cualquier momento, aprovechando algún tipo de turbulencia, podía invadir Castilla y restaurar la hegemonía del grupo o "partido" aragonés en el reino. La amenaza, aunque lejana, podía hacerse realidad algún día. Y si Juan de Navarra recuperaba el control del poder de Castilla, Pacheco, desaparecidos ya don Álvaro de Luna y Juan II, no disponía de muchas cartas para seguir jugando con éxito, tal como había hecho hasta entonces en el tablero político del reino. Es más, una situación como ésta era lo peor que podía sucederle porque, a buen seguro, podía causarle la ruina y la pérdida total de todo lo que había logrado acumular desde 1440, año en el que había iniciado su, hasta ahora, brillante trayectoria política. Había, por tanto, que conseguir la paz, aunque ésta implicarse un alto precio o algún tipo de renuncia. Amo y criado coincidían por completo en que era necesario un acuerdo definitivo con Juan de Navarra, a fin de evitar males mayores.

Las negociaciones con Aragón comenzaron poco después de acceder al trono Enrique IV. Actuó como intermediaria la reina Maria de Aragón, esposa de Alfonso V y hermana del desaparecido Juan II. Tras una serie de complejas e intensas negociaciones -que he estudiado con más detalle en mi biografía de Juan Pachecos- se llegó a un acuerdo definitivo en febrero de 1455. Juan de Navarra se comprometía a renunciar, en una cédula dirigida a Enrique IV el 19 de febrero de ese año, a cualquier derecho o título que pudiese tener sobre la ciudad de Chinchilla y sobre las villas de Alarcón, Albacete, Hellín, Tobarra, Yecla, Sax, Castillo de Garci-Muñoz, Villarejo de Fuentes, San Clemente y Peñafiel. ${ }^{6}$ Todas estas villas que formaban parte del marquesado de Villena, se hallaban por entonces en poder de Juan Pacheco, salvo Peñafiel que había caído en los dominios de Pedro Girón. ${ }^{7}$ Ambos hermanos serían, en consecuencia, los mayores beneficiarios de esta renuncia. La cesión iba acompañada, como sucedía siempre, de una explicación que era, en cualquier caso, pura retórica propia, como era lógico, de un acontecimiento de esta índole; el rey de Navarra lo hacía: "acatando e consyderando prinçipalmente lo que cunple a seruiçio de Dios e al bien común e reposo e tranquilidad e paçificaçion de los regnos e sennorios de amas partes e de todas las Yspanias... acatando que desto se sygue... grand benefiçio e sosiego de toda España, más aún de la mayor parte del pueblo xcristiano...". La altisonante declaración, para dar mayor realce y solemnidad al acuerdo de paz entre los dos monarcas, continuaba con apelaciones a la unidad de la dinastía, separada una sola familia en dos ramas que gobernaban respectivamente sobre Castilla y Aragón: "e así mesmo avido respecto e consideración a los tan grandes e muy cercanos debdos, asi de consaguinidad commo de afinidad que por la graçia de Dios son entre vos y nos, e commo todos ayamos orto e nasçimiento de una e esa mesma Real e Yllustrisima prosapia de la vuestra casa de Castilla".

Juan de Navarra renunciaba a sus derechos sobre esas villas a favor de Pacheco y Girón, pero no lo hacía sin una adecuada compensación económica. Solicitó y obtuvo

${ }^{5}$ Juan Pacheco, privado de Enrique IV de Castilla, Granada, Universidad, 2011.

${ }^{6}$ Archivo Ducal de Frías (En adelante A.D.F.) Catálogo Antiguo, leg. 7, números 1 y 2.

7 Ver a este respecto mis trabajos que explican estas donaciones, FRANCO SILVA, Alfonso, Juan Pacheco. De doncel del príncipe de Asturias a marqués de Villena (1440-1445), Anuario de Estudios Medievales. Barcelona 39/2, (2009), pp. 723-775, y Las intrigas políticas de Juan Pacheco. Del combate de Olmedo a la muerte de Juan II (1445-1454), Anuario de Estudios Medievales. Barcelona. 37/2 (2007), pp. 597-652. 
de Enrique IV a cambio de esa cesión un juro anual de 3.500.000 maravedíes, que le serían situados en varias partidas de rentas reales que fijaría más tarde.

De esta manera, el infante aragonés se desprendía de todo el riquísimo patrimonio que poseía en Castilla, y que en su mayor parte había heredado de su padre, y por el que tanto había luchado e intrigado, no sólo para poder mantenerlo, sino sobre todo para aumentarlo aún más si cabe. Juan de Navarra se comprometía solamente y bajo juramento y pleito homenaje, que hacía en las manos de Enrique de Figueredo, representante de Enrique IV en la negociación y fiel servidor del marqués de Villena, a que cumpliría con todos los términos del tratado. ${ }^{8} \mathrm{El}$ documento de renuncia dedicaba también un jugoso apartado dirigido a Juan Pacheco, a quien se le adulaba en los términos más lisonjeros: "porque vos avés trabajado e procurado con todas vuestras fuerças e todo vuestro leal poder por la pas e concordia e buen amorio del dicho rey de Castilla, nuestro muy caro e muy amado sobrino, e del dicho rey de Aragón, nuestro muy caro e muy amado hermano, e de nuestros reynos... e ansymismo por el gran debdo de sangre e consanguinidad que la marquesa donna María de Puertocarrero, vuestra muger, e con nuestros hijos han con la reyna donna Juana, nuestra muy cara e muy amada muger, e con nuestros fijos, por lo qual deseamos e queremos ser una casa aumentada e acreçentada".

\subsection{LA GUERRA CONTRA GRANADA}

Tras conseguir la paz con Aragón, Enrique IV decide, en abril de 1455, emprender la guerra contra el reino musulmán de Granada. El rey, a fin de comenzar los preparativos, se desplaza a Córdoba. Allí contrae matrimonio con su segunda esposa, Juana de Portugal. La boda fue oficiada por Alonso de Fonseca, un prelado recién elegido arzobispo de Sevilla, y que jugará un destacado papel a todo lo largo del reinado. ${ }^{9}$ En Córdoba, Enrique IV convoca también cortes que van a tener especial importancia para Juan Pacheco. ${ }^{10}$ En efecto, al margen de los temas que en ellas se discutieron y de las decisiones adoptadas, un grupo de procuradores elevó al monarca una petición verdaderamente insólita, y la califico de esa manera no ya porque no podría ser atendida por el rey, que lo haría de buen grado, sino por el contenido expreso de la solicitud. ${ }^{11}$ En efecto, el 5 de junio de ese año ya citado, seis procuradores, arrogándose la representación de todos los que participaban en las cortes -“los procuradores de vuestros regnos que por mandado de vuestra alteza somos llamados e

\footnotetext{
${ }^{8}$ A.D.F. Catálogo Antiguo, leg. 7, números 3 a 9 y leg. 49, números 7 a 9.

9 ENRIQUEZ DEL CASTILLO, Diego, op. cit., pp. 150 y 156; FRANCO SILVA, Alfonso, "E1 Arzobispo de Sevilla Alonso de Fonseca el Viejo. Notas sobre su vida", Boletín de la Real Academia de la Historia. Tomo CXCVI, Cuaderno I, p. 52; SUÁREZ FERNÁNDEZ, Luís, Los Trastámaras de Castilla ..., p. 223. En el torneo que se celebró en Córdoba con motivo de las bodas reales fueron capitanes respectivamente dos enemigos irreconciliables, el duque de Medina Sidonia y Juan Pacheco, hecho éste que según señala ENRÍQUEZ DEL CASTILLO “fue cosa muy señalada de ver", p. 156.

${ }^{10}$ Ver a este respecto la tesis doctoral de OLIVERA SERRANO, César, Cortes de Castilla 1445 1474, Burgos, 1986 y SUÁREZ FERNÁNDEZ, Luis, Enrique IV, pp. 141-144.

${ }_{11}$ A.D.F. Catálogo Antiguo, leg. 34, n5. La confirmación por parte de Enrique IV en Catálogo Antiguo, leg. $6, \mathrm{n}^{\mathrm{o}} 31$ y copia en caja $3, \mathrm{n}^{\circ} 8$.
} 
aquí somos ayuntados en esta vuestra çibdad de Córdoba"-, presentaron a Enrique IV una petición en la que le suplicaban que confirmarse a Juan Pacheco todas las mercedes de villas y tierras que había recibido de su padre, Juan II. La petición, en cuestión, no podía ser más lisonjera para el agraciado: se justificaba la solicitud por los numerosos servicios prestados a la monarquía por el interesado, "los quales han redundado e redundan en onor de la Corona Real de vuestros regnos e paçifico estado e tranquilidad e pro común de ellos". Retórica, sin duda, incluso cuando se manifestaba de manera intencionadamente exagerada que el reconocimiento de esos servicios serviría para "evitar e escusar dellos muchos escándalos e yntolerables e non reparables yncovenientes que en ellos (los reinos) e contra el bien público e pas e sosiego dellos se pudieran seguir”. ¡Como si la paz y la ventura del destino castellano dependiesen de la confirmación a Juan Pacheco de todas las prebendas que hasta ese momento había acumulado! Se mencionaban asimismo todas las donaciones que el marqués de Villena había recibido. Los representantes de las ciudades aprobaban todas estas mercedes, atendiendo a lo dispuesto en las Cortes de Valladolid de 1442, en las que se había dispuesto que no se podían hacer donaciones de villas o lugares "sin el espreso consentimiento de ciertos procuradores, e con acuerdo de los del Consejo o de la mayor parte dellos en número". Esta es, con toda probabilidad, la explicación que había que dar a ese escrito: Pacheco había comprado las voluntades de varios procuradores - no hacía falta que fuesen todos - para que se diese su visto bueno, en virtud de su condición de representantes de las cortes, a las donaciones que había recibido de la Corona. De esta manera se legitimaba y se garantizaba la legalidad de unos señoríos que, en buena parte, como ya hemos mencionado, procedían del bando aragonés derrotado en Olmedo, y que había podido conseguir merced a la magnánima generosidad del príncipe que ahora había accedido al trono. El flamante marqués de Villena, que tenía ya la suficiente experiencia como para no confiar demasiado en su suerte, temía la posible pérdida de su patrimonio en el caso, siempre probable, de que retornase al poder el "partido" que aún dirigía en Aragón el rey de Navarra. Temor éste que no le abandonaría nunca, a pesar de que en varias ocasiones Juan de Navarra le había asegurado por escrito y bajo juramento la renuncia formal y solemne a todas esas posesiones. Aún así, el marqués siempre desconfiaría del futuro rey de Aragón, quizás porque le conocía bien y temía, en consecuencia, que si recuperaba el poder en Castilla, olvidaría sus promesas y le arrebataría sus señoríos. Y sin dominios propios nada sería en el reino. A este respecto, el cronista anónimo de Enrique IV, siguiendo el parecer de Hernando del Pulgar, llega al extremo de sugerir, evidentemente con cierta exageración, que era tal el miedo de Pacheco a la posible pérdida de su patrimonio, que ésta fue la causa de su decidida oposición al matrimonio entre Isabel y Fernando "porque él poseía villas que habian sido de su padre". ${ }^{12}$

${ }_{12}$ A este respecto PULGAR decía que Pacheco "siempre vivió con recelo de lo perder (se refiere al marquesado de Villena), como viven aquellos que poseen cosas agenas. E por lo sostener continuamente ponía indinación entre Enrique IV y Juan II de Aragón, porque la descordia entre estos dos Reyes entendian ser remedio para poseer lo que tenía del marquesado", Crónica de los Reyes Católicos, Tomo LXX de la B.A.E., III, Madrid, 1953, cap. I, p. 241. 
En cualquier caso, fue una inteligente y hábil decisión por parte de Villena recurrir a las cortes a fin de dar mayor legalidad a una decisión regia que, en el futuro, podría ser cuestionada e incluso revocada, como había sucedido en muchas ocasiones en el reino, y de las que el propio personaje había sido testigo en unas y protagonistas en otras. El soborno a los procuradores era una cuestión relativamente fácil en aquellos años en que estos representantes de las ciudades se estaban convirtiendo en una especie de funcionarios a sueldo de la Corona, que corría con todos sus gastos mientras duraban las sesiones de cortes. A este respecto, los seis procuradores que, con el escribano Pedro Sánchez del Castillo, - algunos se describen como humildes siervos del monarca- elevan la petición a Enrique IV, le hacían saber que ya ellos habían aprobado las donaciones a Pacheco, y le habían dado su "expreso asenso e consenso bien así commo si del comienço fuera dado, e todos vuestros regnos las han por bien enpleadas en él, e porque entendemos que cumple así a vuestro seruiçio e a bien de la cosa pública de vuestros regnos, e porque otros tomen dello buen enxemplo para vos seruir en toda lealtad e animosidad". Le piden que, tal como ellos lo han hecho, proceda también el monarca "e gelas faga e otorgue de nuevo para validación dellas".

La respuesta por parte del rey no se hizo esperar. Al día siguiente de recibir esta solicitud, Enrique IV mandaba despachar un privilegio rodado por el que, a petición de los procuradores reunidos en cortes, confirmaba a Juan Pacheco todas las mercedes de villas y lugares que hasta aquel momento había recibido de la Corona. ${ }^{13} \mathrm{La}$ coincidencia de fechas no podía ser de ninguna manera producto de la casualidad, era una prueba más que evidente de la complicidad del monarca en esa más que dudosa petición de los representantes de las ciudades que firmaban la súplica. Dudosa en el sentido de que se cursó para satisfacer la voluntad de Pacheco, con toda seguridad previo soborno o bien bajo la promesa de prebendas para los firmantes de la solicitud, $\mathrm{o}$, tal vez, porque ya eran paniaguados suyos en las ciudades a las que teóricamente decían representar y se habían hecho elegir precisamente para cooperar en la promoción de su protector.

Finalmente, la guerra, o mejor las guerras contra el reino de Granada, constituían también una excelente plataforma para el enriquecimiento personal del privado del monarca. Pacheco era ante todo y sobre todo un político, nunca fue un guerrero, y por ello no parece que su participación en las campañas granadinas fuese, a nivel de hechos de armas, muy destacada. Hernando del Pulgar que le conoció muy bien, parece disculparle a este respecto, cuando dice tan solo que "mostró ser caballero esforçado en algunos lugares que fue necesario". ${ }^{14}$ Ninguno de los cronistas del reinado hacen referencias a combates o batallas, ni siquiera escaramuzas, en las que podría haberse destacado, prueba más que evidente de que la guerra no era lo suyo. En cualquier caso, sabemos que acompañó al rey en la primera entrada que hizo en Granada cuando arrasó las comarcas de Moclín e Yllora ${ }^{15}$ y también en las siguientes, junto a su

${ }^{13}$ A.D.F., Catálogo Antiguo, leg. 6, no 31

14 PULGAR, Hernando del, Los Claros Varones de España, E. Salvat, E. facsímil de la que se imprimió en Sevilla el 24 de abril de 1500, Madrid, 1971, Título VII, pp. 41-46.

${ }^{15}$ Crónica Anónima de Enrique IV, cap. XIV, p. 26. Ver también a este respecto PALENCIA, Alonso de, Crónica de Enrique IV, B.A.E., libro III, cap. VII, pp. 67 y ss. y SUÁREZ FERNÁNDEZ, Los Trastámaras..., pp. 225-226 y Enrique IV, pp. 149 y ss. 
hermano Pedro Girón, cuando se talaron los campos de Archidona, Moclín y Montefrío, y en general en todas aquellas correrías emprendidas por el monarca en la vega de Granada. Fue en 1456, al año de comenzar las campañas, cuando, tras realizar una de esas frecuentes talas en tierras granadinas, Pacheco le pide al rey que le conceda la tenencia de la villa de Estepona, que acababa de ser abandonada por la población musulmana. ${ }^{16}$ Esa villa podía ser, en el plan de Pacheco, la punta de lanza para crear en el futuro un sólido dominio señorial en tierras granadinas próximas a la importante ciudad de Málaga. La petición del marqués estaba perfectamente calculada, más aún cuando intentó convencer al rey de que él era la persona más idónea para poblar la villa de cristianos y defenderla de cualquier ataque que, procedente de Granada, intentase recuperarla. La tenencia de su fortaleza, ya de por sí un jugoso negocio por las partidas de dinero que la Corona debería desembolsar para su defensa, no era más que el primer paso para hacer efectivo el dominio completo sobre la villa y su tierra, además de servir de plataforma para hacerse más adelante con nuevas villas y tierras en esa zona. Enrique IV, tras ciertas vacilaciones, decidió crear una comisión, a fin de que se informase bien de si era posible y viable una defensa eficaz de la villa y su tierra frente a posibles ataques del enemigo. Esa comisión, de la que formaban parte dos personajes afectos a Pacheco, dictaminó a su favor: "la villa se podría bien amparar e defender de los moros", tarea ésta que el marqués podría realizar sin problemas. ${ }^{17}$ En consecuencia, Enrique IV concedió a Pacheco la tenencia de la villa, pero, al hallarse tan próxima a Granada, no era fácil atraer pobladores para asentarse permanentemente en ella, y por consiguiente el monarca se vio en la obligación de conceder generosas franquicias, por un albalá otorgado en Sevilla el 16 de junio de 1456, eximiendo a sus futuros pobladores de toda clase de impuestos y derechos reales. En cualquier caso, como sabemos, este primer intento de poblar Estepona fracasó. Pacheco se vio obligado a ceder la villa al concejo de Jerez de la Frontera, quien se encargó de su defensa, hasta su posterior demolición. ${ }^{18}$ Era imposible en aquel momento, y más aún cuando las campañas se interrumpían poco después sin conseguir resultados apreciables, mantener una villa tan cercana a la frontera granadina.

Es en este contexto en el que hemos querido situar la intervención de Juan Pacheco en el concejo de Jerez de la Frontera, cuando el monarca se hizo acompañar en su estancia en esa ciudad por su privado que, de inmediato, pensó que Jerez y su concejo podrían permitirle crear una base de poder en la Baja Andalucía a fin de neutralizar a su gran enemigo en estas tierras andaluzas, el duque de Medina Sidonia, e intentar, si ello fuera posible, y podía serlo, hacerse de un gran señorío en esta región. ${ }^{19}$ Para ello consiguió de Enrique IV el nombramiento a su favor del oficio de corregidor en Jerez de la Frontera.

${ }^{16}$ Crónica Anónima de Enrique IV, cap. XXVII, p. 55

17 Ibídem

18 A.D.F., Catálogo Antiguo, leg. 9, nº 15. Palencia afirma, con evidente exageración, que el rey concedió a Pacheco 4000 ducados anuales para poblar y defender la villa, cantidad ésta que, según el cronista, la empleó en provecho propio, op. cit., cap. IV, p. 107.

19 VALERA, mosén Diego de, Memorial de Diversas Hazañas. Ed. y estudio Juan DE MATA CARRIAZO, Madrid, 1964. Valera dice que Pacheco había acompañado al rey en su estancia en Jerez, cap. XI, p. 37. 


\section{EL CORREGIMIENTO DE JEREZ DE LA FRONTERA Y LA TENENCIA DE ESTEPONA, PIEZAS ESTRATÉGICAS DEL MARQUÉS DE VILLENA PARA LA "CONQUISTA" DE ANDALUCÍA}

\subsection{EL CORREGIMIENTO EN JEREZ DE LA FRONTERA. ASPECTOS GENERALES}

Como ya señalaba el historiador Hipólito Sancho de Sopranis, la primera vez que se constata la actuación de un corregidor en el concejo jerezano es en 1394, oficio que ejerció Martín Fernández de Portocarrero, señor de Moguer ${ }^{21}$. Desde entonces, la presencia de este delegado del poder real fue haciéndose cada vez más frecuente, hasta que en 1456, el monarca concedió el corregimiento de Jerez a perpetuidad al marqués de Villena, quien lo desempeñó a través de lugartenientes. ${ }^{22}$ El nombramiento de Juan Pacheco debió realizarse poco después de la toma de Estepona, quizás aprovechando la visita que el monarca realizó a la urbe jerezana el 20 de mayo. ${ }^{23}$ Si bien, el primer corregidor designado directamente por el marqués, llamado Tristán Daza, no hizo su entrada en la ciudad hasta varios meses después, en torno al 10 de octubre. ${ }^{24}$ Tras él y de manera excepcional, el corregimiento del marqués fue ejercido por dos alcaldes mayores, quedando éstos al frente de la ciudad desde el 8 de marzo de 1459 hasta, posiblemente, el 1 de octubre de ese mismo año, cuando fue designado para el oficio Andrés de la Plazuela ${ }^{25}$. Tras su breve mandato, el 23 de noviembre de 1459 accedió al cargo

20 Una de las fuentes fundamentales para la realización de este estudio han sido las Actas Capitulares (A.C.) conservadas en el Archivo Municipal de Jerez de la Frontera (A.M.J.F.). En este sentido, consideramos necesario reseñar la ausencia de documentación para los años 1461, 1462 y 1465, así como la irregularidad en la secuencia correspondiente a los años comprendidos entre 1456 y 1465 , período en el que se desarrolla el corregimiento de Pacheco. Además de la inexistencia de las actas de 1456 a partir del 7 de agosto, nos encontramos con sólo 19 folios para el año 1458 y 18 para 1463.

${ }^{21}$ SANCHO DE SOPRANIS, H., Historia de Jerez de la Frontera. Desde su incorporación a los dominios cristianos, Vol. I, Jerez de la Frontera, 1964, p.149

22 Juan ABELLÁN PÉREZ presenta un listado de los corregidores que actuaron en el concejo jerezano desde 1394 a 1454, en El concejo de Jerez de la Frontera en la primera mitad del siglo XV: Composición, sistemas de elección y funcionamiento del cabildo, Jerez de la Frontera, 1990, pp. 29-30. Desde 1455 hasta la llegada del primer corregidor en nombre de Juan Pacheco, ejerció dicho oficio Pedro de Tapia, tal como se constata en las Actas Capitulares de dicho año.

${ }^{23}$ La carta de la concesión del corregimiento al marqués fue asentada en el libro capitular el 11 de octubre de 1456, según se recoge en A.M.J.F., A.C. 1459, fol. 114r. Si bien y como advertimos anteriormente, las actas correspondientes a ese año se interrumpen el 7 de agosto.

${ }^{24}$ Bartolomé Gutiérrez da cuenta de la presentación de una carta en el cabildo del 1 de julio de 1456 en la que se afirma que Pedro de Tapia, corregidor nombrado por el rey en 1455, lo fue también en nombre del marqués: “... vino Gonzalo de Saavedra y presentó la carta en cabildo el jueves primer dia de julio de este año, en donde se hallaban de ayuntamiento el corregidor Pedro de Tapia, que ya lo había sido otra vez por el rey y ahora lo era por el marqués de Villena, que era en propiedad el corregidor...", en GUTIÉRREZ, B., Historia y anales de la Muy Noble y Muy Leal ciudad de Xerez de la Frontera, (edic. facsímil), Vol. I, libro $3^{\circ}$, Jerez de la Frontera, 1989, p. 54; aunque Pedro de Tapia ejerciese el corregimiento en nombre de Pacheco, el primer corregidor designado directamente por el marqués de Villena fue Tristán Daza quien, como decimos, tomó posesión de su oficio en torno al 10 de octubre, según se deduce de un libramiento de pago, A.M.J.F., A.C. 1457, 17r

25 Un traslado de la carta de nombramiento hallado en las Actas Capitulares jerezanas, fecha su designación el 16 de septiembre de 1456 (A.M.J.F., A.C., fol. 99r). Si bien, su entrada en la ciudad no 
Gonzalo Dávila, quien permaneció como corregidor hasta septiembre de 1464, cuando el monarca suspendió el corregimiento de Pacheco debido, sobretodo, al enrarecimiento de las relaciones entre ambos.

La importancia de la figura del corregidor radica en que éste, concentraba enormes atribuciones que le convertían en "el representante por antonomasia de la autoridad y el poder regios en la esfera local", ${ }^{26}$ destacando entre sus competencias, el control del gobierno y la administración de la justicia en el concejo. ${ }^{27} \mathrm{De}$ esta última atribución deriva la primera medida que el corregidor tomaba al llegar a la ciudad: la suspensión de la actuación de los oficiales locales responsables de los dictámenes jurídicos y de su ejecución. ${ }^{28}$

Por su labor, el corregidor gozaba de una quitación anual a la que se añadían los gastos de alojamiento, así como determinados derechos sobre rentas e impuestos. Como ejemplo, analizaremos el desembolso que supuso para las arcas del concejo jerezano la presencia en 1464 de Gonzalo Dávila, corregidor en nombre de Juan Pacheco: en concepto de salario anual se le abonaron 98.200 maravedíes, ${ }^{29}$ cantidad a la que se sumaron otros nueиe mill e seteçientos e dies е пиеиe maravedís e medio del pago de los alquileres de las casas en que moraban él y su alcalde mayor, el bachiller Pedro de la Torre.

Todo ello sin menoscabo de los derechos inherentes a la actuación judicial, ${ }^{30}$ así como de otros ingresos extraordinarios entre los que podemos destacar el

debió producirse hasta primeros de octubre de ese año, según se deduce en la documentación capitular, pues en el cabildo del 31 de octubre, Andrés de la Plazuela solicitó su salario por el mes que llevaba ejerciendo el oficio, A.M.J.F., A.C., 1459, fol. 112v

${ }^{26}$ Así lo define Ma Paz ALONSO ROMERO en El proceso penal en Castilla (siglos XIII-XVIII), Salamanca, 1982, p. 109, aludiendo a Benjamín GONZÁLEZ ALONSO en El corregidor castellano (1348-1808), Madrid, 1970, p. 60.

27 Véase al respecto, BERMÚDEZ AZNAR, A., El corregidor en Castilla durante la Baja Edad Media (1348-1474); LUNENFELD, M., Los corregidores de Isabel la Católica, Barcelona, 1989; GONZÁLEZ ALONSO, B., op. cit. De hecho, en la documentación capitular jerezana, puede observarse cómo el corregidor es llamado en ocasiones "corregidor e justiçia mayor".

28 Un claro ejemplo lo tenemos en la propia documentación capitular jerezana, donde podemos comprobar cómo, tras la llegada de Gonzalo Dávila -corregidor en nombre de Juan Pacheco-, éste nombró "por alcalde mayor e de la justçia desta ciudad en nombre del dicho sennor marqués e en su logar a Garçía del Castillo, bachiller ... ” y “...por alguasil mayor desta çibdad a Garçía de Ferrera ...”, sustituyendo así a los oficiales locales que ejercían dichos oficios, A.M.J.F., A.C. 1459, fols. 115r-v

29 “...dosçientos maravedís cada día e los veinte y quatro mil maravedís que los alcaldes mayores desta çibdad quando los enella ay suelen lleuar de quitaçión con los dichos ofiçios e los mill maravedís de quitaçión con el alcaldía de la justiçia suele lleuar quando lo enella ay, que son asy conplidos los dichos nouenta e ocho mill dosçientos maravedís...". A.M.J.F., A.C. 1464, fols. 5v-6r

30 En las A.C. de 1455, fols. 22r-22v, el corregidor de turno, Pedro de Tapia se dirigió al cabildo solicitando por escrito "...los derechos que pertensçian leuar a el e a sus ofiçiales en los abtos e cosas que les pertenesçia...”, y mandó pregonar que “...cualquier o cualesquier presonas que touiesen quexa de el e de sus ofiçiales asy de derechos que les ouiesen leuado allende de lo que deuían lleuar, o que les fuese fecho o dicho injuria alguna, que viniesen al dicho corregidor e que el las conplería de derecho." Estos derechos a los que se hace referencia, provenían de actividades y tasas judiciales, de la participación en penas pecuniarias y además, de la ejecución de sentencias, tal como señala Isabel RAMOS VÁZQUEZ, en El concejo de Jaén (1474-1556), Universidad de Jaén, 2002. 
tributo de semillas y biscocho ${ }^{31}$ y el derecho a recibir ropa de la ciudad a su llegada. ${ }^{32}$

El corregimiento no se estableció como institución permanente y generalizada hasta el reinado de los Reyes Católicos, por lo que hasta entonces, el nombramiento de dicho oficio -que correspondía al monarca- presentaba un carácter extraordinario, procediéndose a su designación en casos concretos para paliar, como indica José Luis del Pino, “...perturbaciones sociales, la deficiente administración de la justicia o la falta de orden público... sin olvidar los esfuerzos desplegados en determinados periodos por la Corona para controlar y mediatizar mediante este procedimiento la autonomía e independencia, más o menos efectiva del poder local". ${ }^{33}$ En ocasiones, el envío de un corregidor a una ciudad por parte del monarca, se encontraba directamente relacionado con los continuos conflictos originados en los concejos, por la lucha entre las grandes familias aristocráticas locales. En el caso de Jerez de la Frontera, dos eran los linajes en torno a los que se agrupaba la nobleza: los Villavicencio y los Dávila, afines uno a la casa ducal de Medina Sidonia y el otro a la de los Ponce de León. ${ }^{34}$ Esta lucha banderiza sólo pudo ser apaciguada a partir de 1477 , gracias a una decidida política de los Reyes Católicos al respecto y que Jerez, en cierta medida, aceptó debido al "hastío de los bandos y el rechazo de la tiranía ejercida por la alta nobleza sobre los concejos". ${ }^{35}$

\subsection{ANÁLISIS DEL CORREGIMIENTO DE JUAN PACHECO EN JEREZ DE LA FRONTERA}

Si queremos conocer la verdadera significación histórica del corregimiento ejercido por el marqués de Villena en el concejo jerezano, debemos profundizar en el estudio

${ }^{31}$ Éste era un derecho que gravaba la exportación de semilla y pan, y por el que el corregidor cobraba una cantidad de maravedíes por cada quintal exportado, cuantía que no ha podido ser determinada tras el estudio de la documentación consultada. Lo que sí hemos podido constatar es que era un derecho que se abonaba con ciertas reticencias por el concejo. Tanto es así que, en 1464, los regidores García Dávila y Pedro Núñez intentaron que nunca más se cobrara este tributo: "E luego el dicho Garçía de Auila regidor, dixo que el era e es en que el dicho derecho e mal tributo que en las dichas semillas e biscocho era puesto por los dichos corregidores se quitase e non lleuase... ", A.M.J.F., A.C. 1464, fols. 180v-181r

${ }_{32}$ El corregidor Gonzalo Dávila, a su llegada a la ciudad, recordaba al cabildo cómo “...es costunbre en esta çibdad que cada que a ella viene corregidor le es dada ropa por esta çibdad la que le es necesaria e que el era venido a esta çibdad nuevamente e que el auia menester ropa para en que fuese aposentado el e su gente que el non era menos que los corregidores que a esta çibdad eran venidos, pidioles le mandasen dar toda la ropa que ouiese menester para él e para su gente por que el fuese prestamente aposentado e la justicia del rey nuestro sennor fuese asentada", A.M.J.F., A.C. fol. 1459, 115v.

${ }^{33}$ DEL PINO GARCÍA, José Luis, "El concejo de Córdoba a fines de la Edad Media: Estructura interna y política municipal", Historia, Instituciones y Documentos $_{2}$ Sevilla, 1993, n²0, p. 359

${ }^{34}$ La lucha entre distintos bandos de la aristocracia local fue uno de los principales motivos argüidos por la monarquía castellana para el envío de corregidores a los concejos. LUNENFELD, M., op. cit., pp. 65-67

35 SÁNCHEZ SAUS, Rafael, Linajes medievales de Jerez de la Frontera, 2 Vols., Sevilla, 1996, p.22; para el estudio de las luchas banderizas en la ciudad jerezana es fundamental citar a MORENO DE GUERRA, Juan, Bandos en Jerez. Los del Puesto de Abajo. Estudio social y genealógico de la Edad Media en las fronteras del reino moro de Granada. Madrid, 1929. 
de las connotaciones especiales que presenta, más allá del mero análisis institucional del oficio. En este sentido, destacamos como un primer aspecto a tener en cuenta, la concesión a perpetuidad del corregimiento a Juan Pacheco, puesto que en circunstancias normales, este cargo tenía un carácter excepcional y una duración determinada. ${ }^{36}$ Estas irregularidades en el nombramiento del marqués, pueden explicarse si tenemos en cuenta tres elementos básicos:

Por un lado, la tendencia de la monarquía a centralizar y controlar cada uno de los resortes del gobierno de la Corona. En este sentido, el nombramiento de Juan Pacheco como corregidor perpetuo de Jerez, suponía para el rey castellano el establecimiento de un delegado directo y permanente de su poder, en uno de los concejos más importantes del reino sevillano. De hecho, podemos afirmar que la intención del monarca respecto al corregimiento fue la de "...lograr que poco a poco, lo que en inicio era un oficial extraordinario justificado en el derecho a corregir, al que nunca renunció el monarca, se convirtiera en un cargo municipal ordinario, institucionalizando así de derecho la gestión interna de los municipios." ${ }^{37}$

Por otro lado, debemos tener en cuenta una práctica habitual de los monarcas castellanos a la hora de pagar fidelidades y servicios prestados por la nobleza. Nos referimos a la concesión de mercedes regias entre las que se encontraba la asignación de oficios y cargos públicos como moneda de cambio, algo en lo que se prodigaron especialmente Juan II y Enrique IV. ${ }^{38}$

Finalmente, no podemos olvidar las especiales relaciones que existieron entre los dos personajes implicados, el monarca Enrique IV y el marqués de Villena. Para ilustrar el caso, traemos a colación la magnífica descripción realizada por José Manuel González Infante que, habiendo estudiado en profundidad la personalidad, tanto del monarca como de Pacheco y las relaciones que entre ellos se establecieron, afirma que “...la sola presencia del marqués de Villena generaba en el rey un tal torbellino emocional, que sólo el bloqueo psíquico general era capaz de contrarrestar su intensa ansiedad y profundo desasosiego...". Únicamente así puede entenderse “...el incomprensible comportamiento de Enrique IV, a tenor de cómo las sugerencias del señor de Villena, eran auténticas sugestiones para el rey". González Infante describe la personalidad de Enrique IV como la de un rey caracterizado por “...la inseguridad y la timidez, la carencia de iniciativa, una dotación intelectual de nivel medio o medio bajo, un pensamiento de fuerte raigambre paleológica, marcados sentimientos

36 En las Cortes de Valladolid de 1442 se determinó la duración del corregimiento, no pudiendo éste sobrepasar los dos años, en ABELLÁN PÉREZ, J., op.cit., p. 38. El corregidor era designado, en principio, por un año, pudiéndose prorrogar su ejercicio un año más si resultaba necesario. Esta regulación no debió ser respetada por el monarca pues de nuevo en las Cortes de Toledo de 1462, los procuradores de las ciudades insistían en que se cumpliera dicha normativa, a lo que el monarca, como en otras ocasiones, respondió de manera favorable: “...pero si yo entendiere que cumple a mi seruiçio que algund corregidor este otro anno de mas del primero que ouiere estado, que avida informaçión como uso bien, le pueda ser prorrogado otro anno e non mas...", en Cortes de los Antiguos Reinos de León y Castilla, pub. REAL ACADEMIA DE LA HISTORIA, Vol. III, Madrid, 1861-1884, pp.704-705

37 GUERRERO NAVARRETE, Yolanda: "La política de nombramiento de corregidores en el siglo XV. Entre la estrategia regia y la oposición ciudadana", en Anales de la Universidad de Alicante. Historia Medieval, $\mathrm{n}^{\circ}$ 10, 1994-95, p. 105.

${ }^{38}$ GARCÍA MARÍN, José María: El oficio público en Castilla durante la Baja Edad Media, Madrid, 1987, p. 127 
de inferioridad y pérdida de la autoestima, y una moralidad timorata". Por otra parte, de Juan Pacheco destaca que, "...frente a la anormal personalidad del rey se situaba un colosal adversario, que a su inteligencia brillante y a una total falta de escrúpulos, asociaba un perfecto conocimiento de las aptitudes del monarca, lo que le permite siempre, más que convencer, sugestionar, al soberano hasta el extremo de llegar a hacer suyo el pensamiento que Pacheco le imponía..." ${ }^{39}$ Consideramos las peculiaridades de ambas personalidades, así como las relaciones establecidas entre uno y otro, un punto de partida desde el que poder explicar los turbulentos acontecimientos históricos de este período.

Una vez descritas las principales causas de la designación perpetua del corregimiento de Pacheco en Jerez, queda por responder a otra cuestión no menos importante: ¿por qué aceptó el concejo jerezano con tanta condescendencia una anomalía tan evidente en la designación del oficio de corregidor? Este hecho llama especialmente la atención si tenemos en cuenta el carácter contestatario de la ciudad y la tendencia general de los municipios castellanos a negarse a la designación de este alto oficial, si no era con la petición expresa del concejo. Esto nos hace suponer que, antes de su nombramiento, Pacheco debió tejer una importante red clientelar en la que integró a los principales miembros de la aristocracia jerezana. Una buena oportunidad para ello, pudo presentarse en las campañas militares contra Granada, llevadas a cabo en 1455 por el monarca castellano y en las que también participó Pacheco. Fue allí donde pudo haber establecido los primeros contactos con caballeros jerezanos en el mismo campo de batalla, ganándose su favor y logrando con ello una mejor acogida como corregidor.

Continuando con el análisis del corregimiento de Pacheco, otro aspecto a tener en cuenta es la importancia que este oficio tenía para el marqués como pieza clave para conseguir su establecimiento en Andalucía. ${ }^{40}$ Gobernar el cabildo xericiense a través de su corregimiento, suponía mucho más que el dominio de una ciudad, ya que era un núcleo estratégico en la comarca desde el punto de vista socio-económico y también en la lucha contra Granada. Pero además, gobernar Jerez significaba controlar un oasis de realengo en un territorio fuertemente dominado por la nobleza regional.

39 Estas son las conclusiones planteadas por José Manuel GONZÁLEZ INFANTE en su tesis inédita Estudio historiográfico, psicológico y psicopatológico del Rey Enrique IV de Castilla, 2008, Universidad de Cádiz, dirigida por Alfonso Franco Silva, pp. 141, 178, 179.

40 Además del corregimiento en Jerez de la Frontera, Juan Pacheco contó para su proyecto en Andalucía con el oficio de alcalde mayor de Sevilla, merced ésta también concedida por el monarca y que el marqués desempeñó mediante lugartenientes. Entre otros, actuó como delegado de Pacheco Martín Fernández de Portocarrero, que se hallaba ejerciendo como teniente de alcalde mayor en Sevilla en 1453, según señala Ma Asunción VILAPLANA en "La aceptación de D. Enrique de Guzmán como futuro alcalde Mayor de Sevilla", en Historia, Instituciones y Documentos, no 19, 1992, p. 472; otro de alcaldes mayores que actuaron en nombre del marqués, fue Juan Alfonso de Galmes a quien, en la documentación capitular jerezana de 1454, el monarca se dirigía como "...teniente lugar de alcalde mayor por don Juan Pacheco, marqués de Villena, e mi vasallo e del mi consejo e mi alcalde mayor de la muy noble e muy leal çibdad de Seuilla...". Todavía en 1457 se encontraba ejerciendo este oficio, A.M.J.F., A.C. 1457, 49v y ss. No cabe duda de que una alcaldía mayor, nada más y nada menos que en el concejo sevillano, permitía al marqués crear una base de poder sobre la ciudad hispalense y su comarca, una de las más importantes del momento, especialmente interesante si tenemos en cuenta los particulares vínculos socio-económicos existentes entre los concejos de Sevilla y Jerez. 
De igual manera, Pacheco sabía que necesitaba influir en el concejo jerezano para afianzar y ampliar las redes clientelares que había comenzado a forjar en la comarca. En esta tarea contó con el apoyo de su hermano, Pedro Girón, maestre de Calatrava, frontero y capitán general desde $1456,{ }^{41}$ quien ya había conseguido una amplia red clientelar en diversas zonas andaluzas, entre ellas Jerez.42

En cualquier caso, a pesar de que el titular del corregimiento era Juan Pacheco, quien realmente llegaba a Jerez para ejercer el cargo no era el señor de Villena, sino su lugarteniente, quien debía ganarse el respeto del concejo con una correcta práctica de su oficio ${ }^{43}$ El mayor o menor éxito del corregidor estaba determinado, además de por las cualidades personales del oficial, por la singular fuerza que el regimiento jerezano había adquirido, gracias a las excepcionales relaciones establecidas entre el concejo y los monarcas castellanos, conocedores éstos de la importancia que Jerez de la Frontera tenía como bastión de realengo en la zona y como base en la guerra contra Granada. Uno de los casos que mejor ilustran esta circunstancia, es el del asesinato del alcalde mayor Juan García de Castro y la expulsión de Tristán Daza, lugarteniente de Pacheco, hecho que brevemente narraremos a continuación:

Los excesos e irregularidades cometidas por Juan García de Castro -alcalde mayor nombrado por el corregidor Tristán Daza-, desencadenaron una turbia venganza por parte de un nutrido grupo de vecinos jerezanos. ${ }^{44}$ Concretamente, el 6 de marzo de $1459,{ }^{45}$ indignados por determinadas actuaciones del alcalde mayor, "...se juntaron algunos caballeros que de ellos fueron los más conocidos Gonzalo Pérez de Gallegos y su hermano Juan con otros Vargas y yendo a la casa en que vivía lo acuchillaron, dejándolo como muerto..." ${ }^{46}$ Tras este suceso, sorprendentemente el concejo justificó los hechos y para evitar males mayores ordenó la expulsión del corregidor Tristán Daza, quien antes de partir, debía nombrar a dos nuevos alcaldes mayores y a un alguacil que serían, momentáneamente y de manera excepcional, los nuevos encargados de ejercer el poder en nombre de Pacheco, hasta que el marqués o el monar-

41 VALERA, D., op. cit., p.40

42 Alonso de Palencia afirmaba, refiriéndose a Pedro Girón, que "los sevillanos, aunque honraban mucho al duque de Medina y al Conde de Arcos, le seguian en aquella guerra. También tenía a su devoción Jerez y Carmona ...”, op.cit., p.183. Un ejemplo concreto de esta connivencia lo tenemos en la figura del regidor jerezano Pedro Fernández de Vera, quien según recoge Bartolomé Gutiérrez, vivía con el Maestre de Calatrava, op.cit., p. 54.

${ }^{43}$ Acorde con esta idea, Marvin LUNENFELD afirma que "los corregidores resultan ser fuertes o débiles según las ciudades, las épocas, las tradiciones y privilegios de un municipio, la unidad de la elite municipal, el grado fluctuante de apoyo que los corregidores recibian de sus superiores y sus propias aptitudes personales", op.cit., p. 16

${ }^{44}$ Tras la consulta de las crónicas de la época, las causas del asesinato no han podido ser concretadas. Todo apunta a que este suceso debió tener su origen en los abusos y mala praxis ejercida por el alcalde y los oficiales del corregidor. Por su parte, Alonso de Palencia, que narra una versión algo distinta a la de los cronistas jerezanos y confunde al alcalde Juan García de Castro con el corregidor, señala como causa del asesinato una "...acusación de adulterio..." en la que habría estado implicado dicho alcalde, op.cit., libro VI, cap. VI, p. 136

${ }^{45}$ GUTIÉRREZ, B., op.cit., p. 30; según Fray Esteban RALLÓN, fue el día 7, en Historia de la ciudad de Xerez de la Frontera y de los reyes que la dominaron desde su primera fundación, Vol. II, edición de MARÍN RAMÍREZ, J.A. y MARTÍN GUTIÉRREZ, E., Jerez de la Frontera, 1997, p. 264

${ }^{46}$ GUTIÉRREZ, B., ibídem. 
ca determinasen sobre el asunto. Recayeron estas alcaldías en los regidores García Dávila y en Iñigo López, y el alguacilazgo en el jurado Juan Fernández de Torres. ${ }^{47}$ Acto seguido, el cabildo formó una comisión delegada con el objetivo de explicar lo sucedido tanto a Juan Pacheco como al propio monarca, siendo designados para tal empeño el jurado Francisco de Vera y su hermano, Pedro de Vera. Entretanto, Juan García de Castro, que había sobrevivido a la agresión, quedó bajo custodia del concejo hasta su recuperación, momento éste en que sería enviado como acusado a la corte. Pero antes de que esto ocurriera, “...los agraviados del herido y preso alcalde mayor...una noche se juntaron y a mas de las 12 se arrojaron á la cárcel y con hachas de hierro quebrantaron las puertas y con belas de cera encendidas entraron dentro y buscaron al referido acuchillado, le dieron muerte, cortándole la cabeza y arrojándola a la calle". ${ }^{48}$

Este hecho complicaba las negociaciones que la comisión formada por los hermanos Vera debía realizar para tratar de suavizar las sanciones que, sin duda, serían impuestas a los culpables. Una vez la delegación jerezana consiguió entrevistarse con Juan Pacheco, ésta basó su alegato en que todo lo ocurrido derivaba de los abusos cometidos por el alcalde mayor y sus oficiales, a lo que el marqués respondió que “... aunque ello fuese asi y aquellos delitos mereciesen, como merecían, mayor castigo, que había sido notable el atrevimiento de aquellos caballeros, en tomarse ellos la mano para castigarlos, era menosprecio de su autoridad a quien como a justicia mayor de esta ciudad competía el conocimiento y causa y castigo de la culpa que era fuerza...". Pero lejos de la contundencia empleada por Pacheco en otros momentos, el marqués, aunque indignado por lo ocurrido, decidió servir de intermediario entre el rey y el concejo de Jerez en este caso. El suceso finalizó con el envío a la ciudad de un pesquisidor, el bachiller Juan González de Sepúlveda, quien llevó a cabo las investigaciones necesarias para poder emitir sentencia. Pero si acudimos a las fuentes de la época, las penas impuestas a los culpables fueron sospechosamente benévolas. ${ }^{49}$

47 Ofrecemos aquí un fragmento del requerimiento realizado por el concejo jerezano al corregidor Tristán Daza: "Yo García Dávila reidor é Juan de Torres Jurado, en nombre de los 13 regidores caballeros y de los jurados en nombre de los jurados de esta ciudad vos decimos que bien sabedes como diz que por los merecimientos del Bachiller Juan García de Castro, vuestro lugarteniente en esta ciudad y por los grandes excesos y grandes delitos por él cometidos...le acuchillaron...y vos, como quier que seades caballero honrado y fidalgo pero sódesle muy sospechoso a esta ciudad y a los vecinos $y$ moradores de ella...por ende pedimos y requerimos y afrontamos; que luego sin otra dilación ni tardanza cometades, y en comendedes la justicia y corregimiento y alguacilazgo, según que lo tenedes, á buenas personas sin sospecha, que los usen hasta que el Sr. Rey sea servido y requerido sobre ello y S.M. determínelo conplidero á su servicio cá asi mismo que asi como desde los dichos oficios vos vayades luego de esta causa y fuera de su término donde á vos plegueis...”, ibídem, p. 31.

48 Ibídem; Fray Esteban RALLÓN sitúa la fecha del asesinato del alcalde mayor el 5 de mayo, op.cit., p. 268.

49 El cronista jerezano así lo atestigua: "En un memorial antiguo hallé que no fue este oidor tan riguroso en los fines como entero en los principios y da a entender que con el trato y comunicación de los caballeros y con la certeza de las maldades que el alcalde mayor muerto y Tristán Daza y sus alguaciles habian cometido, ablandó la indignación con que venia". RALLÓN, Fray Esteban, op.cit., pp. 271-272. Este autor considera la posibilidad de que los culpables expiaran sus penas sirviendo militarmente año y medio en la villa de Jimena. 
Desde cualquier punto de vista, el episodio descrito evidencia un gran atrevimiento por parte de los implicados y también del concejo jerezano, por un lado, contra la autoridad del corregidor Tristán Daza, por otro, contra Juan Pacheco como titular del oficio y también, contra el propio monarca, fuente de todo poder. Esto nos lleva plantear una nueva cuestión: ¿qué elementos tuvo en cuenta el marqués para no tomar medidas ejemplares contra los culpables de un crimen tan alevoso y que además suponía un flagrante desacato a su autoridad como corregidor? Uno de ellos pudo ser la implicación en este suceso de personajes relevantes de la sociedad jerezana, entre los que destacaríamos al regidor Gonzalo Pérez de Gallegos y a sus hermanos, Martín y Diego González. Además de estos nombres, el cronista Esteban Rallón menciona como involucrado a un personaje llamado Pedro de Vera, sin especificar si se refiere al regidor Pedro Fernández de Vera, ${ }^{50}$ a Pedro de Vera Mendoza -el que fuera corregidor de Cádiz- o a Pedro de Vera Trujillo, que aparece en las fuentes como mayordomo de Jimena en $1467 .{ }^{51} \mathrm{En}$ el caso de que se refiriese al primero, al regidor Pedro Fernández de Vera, podríamos afirmar como una de las causas de la tibia actuación de Pacheco, el hecho de que entre los inculpados hubiese personas cercanas a su círculo clientelar. Concretamente, este personaje pertenecía a la casa del maestre de Calatrava, Pedro Girón. Al no poder ser contrastada esta hipótesis, únicamente lo tratamos aquí como algo probable. ${ }^{52}$ Otro de los elementos que debió considerar el marqués, fue la implicación en el asesinato de un numeroso grupo de jerezanos: tomar severas medidas penales contra todos los responsables y copartícipes, habría supuesto poner en peligro la paz y el control de la ciudad..$^{53}$ En este sentido, es posible explicar la actitud del marqués como un gesto necesario para no crearse enemistades en Jerez, ya que éste concejo debía de proporcionarle una base sólida desde la que poder penetrar en Andalucía con ciertas garantías de éxito. Tampoco debemos descartar, como otra posible causa de la posición tan sumamente transigente del marqués, la presencia entre los implicados en el crimen, de miembros sobresalientes de linajes jerezanos afines al duque de Medina Sidonia, principal enemigo de Pacheco en la región..$^{54} \mathrm{El}$ hecho de que varios de los participantes y cómplices del asesinato fuesen partidarios de la casa de Niebla, posiblemente alertó al marqués y le hizo comprender que, una contundente represalia podía ser vista en la ciudad como un ataque directo a dicho bando, provocando un

${ }^{50}$ Quien en ocasiones es mencionado en las Actas Capitulares como Pedro de Vera.

51 RALLÓN, Fray Esteban, op.cit., p. 264

52 Estos tres personajes son mencionados por Rafael SÁNCHEZ SAUS como miembros del linaje de los Vera para el período que estamos analizando, op. cit., Vol. I, pp.198-208 y vol. II, pp. 306-307.

${ }_{53}$ Aunque tanto Bartolomé GUTIÉRREZ como Fray Esteban RALLÓN, sólo aportan el nombre de unos pocos acusados, éste último, al relatar la sucesión de los hechos indica que, tras ser asesinado el alcalde mayor, los autores del homicidio se refugiaron en el convento de San Francisco oponiendo fuerte resistencia a los que venían en nombre de la justicia, sin poder ser reducidos. Esto ocurrió, o bien por un elevado número de personas involucradas y/o por la lasitud de las autoridades municipales en su represión, op.cit., p. 269

${ }^{54}$ Rafael SÁNCHEZ SAUS evidencia la pertenencia a la casa de Niebla tanto de Gonzalo Pérez de Gallegos como de su hermano Diego González de Gallegos, implicados en el crimen, op.cit., vol. I, pp. 89-90; en esta misma línea, Iñigo López de Carrizosa, afín a la casa del duque de Medina, "en 1462 se encontraba suspendido en sus funciones por el turbio asunto, al parecer relacionado con algún agravio deshonroso, de la muerte del alcalde mayor Juan García de Castro", ibídem, pp. 111-112. 
aumento de las luchas banderizas y, quien sabe, la intervención directa del propio Juan de Guzmán a favor de sus partidarios.

Una vez examinado este episodio, y continuando con el análisis de la política del marqués de Villena como corregidor de Jerez, cabe preguntarse, ¿cómo consiguió Juan Pacheco el apoyo de una ciudad, dividida entre partidarios de Ponces y Guzmanes, y en la que comenzaba a dejarse ver también la influencia de Beltrán de la Cueva, principal adversario de Pacheco? Para conseguir el favor del concejo jerezano, el marqués desarrolló una política de acercamiento a determinados personajes sobresalientes de la sociedad jerezana, a los que agasajó con mercedes y parcelas de poder a cambio de apoyo político. ${ }^{55}$ Es más, lejos de actuar con hostilidad hacia los partidarios de sus enemigos, el marqués usó con ellos una estrategia de aproximación y atracción a su causa. Un ejemplo de esto lo tenemos en la intervención directa de Juan Pacheco para que el cabildo jerezano aceptase al jurado Esteban de Villacreces como "bos de asystente" ${ }^{56}$ Este hecho adquiere especial relevancia, si tenemos en cuenta que Esteban de Villacreces era cuñado de don Beltrán de la Cueva y que además, ejercía la alcaidía de Jimena en su nombre. ${ }^{57}$

Concretamente, en el año 1457, el rey hizo merced a Esteban de Villacreces del oficio de "bos de asystente", que supuestamente había sido desempeñado años atrás por el regidor Ferrand Ruiz Cabeza de Vaca, recientemente fallecido. ${ }^{58}$ Aunque algunos miembros del cabildo aceptaron este nombramiento, varios regidores se negaron argumentando que Ferrand Ruiz Cabeza de Vaca no había ejercido el oficio de voz de asistente, sino que había tenido una regiduría acrecentada que, según las leyes del reino, debía consumirse con el finamiento de la persona que poseía dicha merced. ${ }^{59}$ Tristán Daza, lugarteniente de Juan Pacheco, ante esta tesitura optó por remitir el caso al monarca, para que éste confirmara o revocara dicha merced. ${ }^{60}$ Todo este proceso concluyó con el envío al concejo jerezano de “...una çedula del dicho sennor rey e asy mesmo carta del señor marqués...” en las que se advierte cómo el monarca,

${ }^{55}$ Este aspecto será estudiado con mayor profundidad en un apartado posterior que tratará sobre la red clientelar de Pacheco en Jerez.

${ }^{56}$ Las funciones y competencias de este oficio no quedan descritas en la documentación consultada. El caso lo analiza en profundidad Juan ABELLÁN PÉREZ en su artículo "División del cabildo jerezano ante el nombramiento de Esteban de Villacreces como Voz de Asistente (1457)", en Homenaje al profesor Juan Torres Fontes, Vol. 1, 1987, pp. 13-24

57 El jurado jerezano estaba casado con Leonor de la Cueva, hermana de don Beltrán. Puede consultarse información biográfica de Esteban de Villacreces en SÁNCHEZ SAUS, R., op.cit, Vol. I, pp. 211-213.

${ }^{58}$ A.M.J.F., A.C., 1457, fols. 28r-v; las fuentes capitulares jerezanas no registran en ningún momento la actuación de este regidor como voz de asistente. Es posible que el oficio le fuese otorgado pero que nunca se hiciese efectivo.

59 A.M.J.F., A.C., 1457, fol. 31r

${ }^{60}$ La actitud tomada por este corregidor solía ser muy habitual, según documentamos en las Actas Capitulares jerezanas. Cuando en el cabildo había al menos siete voçes, es decir, la mayoría (ya que el cabildo estaba formado en principio por 13 regidores del número), el corregidor aceptaba la decisión adoptada por los capitulares. Pero cuando el asunto que se trataba era de gran importancia, como es el caso del nombramiento de un oficial, aunque hubiese mayoría simple en el cabildo, el corregidor solía aplazar su decisión a expensas de una confirmación real o en su defecto del titular del corregimiento, Juan Pacheco. 
ante la negativa del cabildo a aceptar a Esteban de Villacreces como "bos de asystente", revocó esta concesión, rectificando y concediendo al jurado jerezano "bos e voto en el cabildo segund que la tyene cada uno de los regidores". Es decir, otorgó a Esteban de Villacreces una regiduría acrecentada ${ }^{61}$ Por su parte, Pacheco, lejos de actuar en contra de quien era cuñado de su mayor enemigo, no perdió la oportunidad para mostrarse como un benefactor de Esteban de Villacreces, al solicitar directamente al cabildo que lo aceptaran como regidor. ${ }^{62}$ Pero como ya había ocurrido en otras ocasiones, el caso finalizó con una muestra más de autonomía y fuerza del concejo jerezano, que se negó a aceptar a Esteban de Villacreces a pesar de recibir la orden directa del monarca y del propio Juan Pacheco.

Otra de las armas empleadas por el marqués para ganarse el apoyo de Jerez, fue la de mostrarse como protector del concejo. Encontramos un buen ejemplo de ello en la sesión capitular del viernes 8 de julio de 1457, en la que regidores y jurados de común acuerdo, propusieron obsequiar a Juan Pacheco con dos caballos valorados en 20.000 maravedíes, en agradecimiento por los servicios prestados a la ciudad, y cuya compra fue encargada, no por casualidad, al regidor García Dávila, afín al marqués, y al caballero jerezano Agustín de Spínola, que en nombre del corregidor ejercía la alcaidía de Estepona.$^{63}$ El cabildo destacaba tres hechos como motivos principales de esta decisión: en primer lugar, la intermediación del marqués para conseguir una reducción en los gastos que provenían del mantenimiento de la villa de Jimena, por entonces a cargo del concejo jerezano. En segundo lugar, los capitulares valoraban positivamente su intervención para impedir la concesión perpetua, por parte del monarca, del alguacilazgo mayor de la ciudad a Juan de Valenzuela. ${ }^{64} \mathrm{Y}$ finalmente, fue tenida en cuenta la mediación del marqués para eximir a la ciudad de un seruiçio militar en la vega granadina.

En principio, la actuación de Pacheco puede parecer un gesto irrefutable de protección y apoyo al concejo jerezano, pero conociendo la personalidad del marqués, no es extraño pensar que actuó con una doble intencionalidad: por un lado, con la disminución de las ayudas que Jerez debía prestar a Jimena, el marqués conseguía perjudicar a Beltrán de la Cueva, señor de dicha villa. Por otro lado, para entender la oposición de Pacheco a que se le concediera el alguacilazgo mayor del concejo a Juan

${ }^{61}$ A.M.J.F., A.C., 1457, fol. 48r

62 En la carta remitida por el marqués, éste se expresa en los siguientes términos: "Conçejo, regidores, jurados, ofiçiales e omes buenos de la çibdad de Xeres. Mis buenos amigos, resçebi las cartas que me enbiastes açerca del fecho de Esteuan de Villacreçes de lo qual el rey mi sennor proueó en manera que la merced que tenía para ser asystente fue reuocada e annulada e fue proueydo que entrase en los cabildos e ayuntamientos con vosotros segund e conmo regidor deue entrare estar, paresçeme que esto es cosa que se puede faser con rasón, por tanto deueys consentyr en la dicha carta e conplidla segund por ella vos es mandado e darle lugar conmo de aqui adelante entre con vosotros en vuestros ayuntamientos conmo un regidor que gose de las perrogatyuas e que vosotros gozades, que aquesta cosa justa, rasonable es e no lo deuedes retraer nin faser sobre más gastar al dicho Esteuan. Este vuestro mensajero soleçito bien este fecho e con diligençia justo es que él sea bien satysfecho de su salario, sea nuestro sennor en vuestra guarda, de Santo Domino a veynte de abril, quien vuestra onrra desea, el marqués”, A.M.J.F., A.C., 1457, fol. 48r

${ }^{63} \mathrm{El}$ caso puede seguirse en A.M.J.F., A.C. 1457, fols. $65 \mathrm{r}-\mathrm{v}$

${ }^{64}$ Las fuentes sólo lo nombran sin aportar más datos al respecto, si bien, parece que se trataba del prior de la Orden de San Juan. 
de Valenzuela, debemos tener en cuenta que este personaje no era partidario del marqués. De hecho sería posteriormente apresado por Pedro Girón al negarse a reconocer como rey a don Alfonso, cuando éste fue entronizado en la llamada farsa de Ávila. Y en cuanto a la eventual exención militar obtenida por Pacheco para Jerez, el marqués lograba con ello, además de mantener la ciudad en un estado de ánimo proclive a su servicio, reservar intactos los recursos xericienses para auxiliar a Estepona cuando fuese necesario.

\subsection{LA RED CLIENTELAR DEL MARQUÉS DE VILLENA EN LA COMARCA JEREZANA}

Las pretensiones de Juan Pacheco en Andalucía requerían la creación de una red clientelar en la región, algo que consiguió sobradamente. Pero, ¿cómo pudo el marqués urdir una compleja red en un territorio dominado por el conde de Arcos y, especialmente, por el duque de Medina Sidonia? ¿Con qué medios contó y cuáles fueron las maniobras que realizó para la consecución de tal propósito? Para responder a estas interrogantes nos valdremos del análisis de las relaciones que Juan Pacheco estableció con algunas de las principales personalidades del concejo jerezano.

Comenzaremos estudiando a uno de los personajes más importantes y de mayor influencia en Jerez de la Frontera desde mediados del siglo XV. Nos referimos al regidor García Dávila, que desempeñaba dicho oficio desde 1450 y que pertenecía a uno de los linajes más poderosos del concejo jerezano. ${ }^{65} \mathrm{~A}$ la llegada de Pacheco, era ya una figura con un enorme peso en la ciudad y en el cabildo, donde su voto era seguido por gran parte de los regidores. Por ello, el marqués buscó y consiguió su apoyo, llevándose a cabo una relación simbiótica entre ambos: Pacheco favorecería a García Dávila, y éste, a cambio, sería su mayor partidario en el concejo. Un ejemplo significativo de este vínculo lo podemos constatar a través del análisis de una disputa que tuvo lugar en 1459 y que se originó por el intento de García Dávila, de hacerse con el oficio de mayordomo mayor del concejo, cargo anual y electo, al que no podían acceder ni jurados, ni regidores. ${ }^{66}$

Frente al resto de candidatos que se habían presentado a la elección, el regidor contó con el apoyo directo, nada más y nada menos, que del propio marqués, quien

${ }^{65}$ El linaje Dávila, en líneas generales, apoyaba a la casa de Arcos frente a la familia jerezana de los Villavicencio, partidarios del duque de Medina Sidonia.

${ }^{66}$ Según los privilegios de la ciudad, este oficio se reservaba anualmente a la población pechera, si bien, las irregularidades al respecto abundaban y se puede observar a los regidores Pedro Núñez de Villavicencio y Bartolomé Núñez de Villavicencio, actuando como mayordomos del concejo en 1454 y 1457 respectivamente, A.M.J.F., A.C. 1454 y 1457. El mayordomo, además de controlar las arcas jerezanas, recibía una retribución en torno a los 50.000 maravedís. García Dávila, en su requerimiento para ser aceptado como mayordomo mayor, amenazó al corregidor Tristán Daza con exigirle a él, el pago de los maravedíes que le correspondían por dicho oficio: “...y de cobrar de vos e de los vuestros bienes çinquenta mill maravedis que me puede rentar el dicho ofiçio de mayordomadgo este dicho anno...”, A.M.J.F., A.C. 1459, 8r-v. Para seguir pormenorizadamente este episodio, véase ABELLÁN PÉREZ, J., "Transgresión de la normativa seguida en Jerez de la Frontera en la designación de los oficios anuales: La mayordomía de 1459", en Estudios sobre patrimonio, cultura y ciencia medievales, $\mathrm{n}^{\circ} 2,2000$, pp. 7-20 
con la pretensión de satisfacer y premiar la fidelidad de García Dávila, se dirigió al cabildo en estos términos:

"Mis buenos parientes e amigos, ya sabeys conmo Gutierre de Padilla es criado mío y a la verdad, es persona de quien tengo cargo porque me ha bien seruido y por esto yo he voluntad de le ayudar en todas cosas, por ende yo vos pido graçia que por mi contenplaçión deys orden conmo el sea nonbrado en esa çibdad por mayordomo para el anno que viene, asy conmo otras veses se acostunbra faser a otras personas y por que el sienta que por respeto e contenplaçión mía se tyene con él, esta manera creed que reçibiré mucha graçia en que asy se faga y por que él, conmo sabeys, anda contynuadamente syruiéndome por mi amor, que en su lugar sea nonbrado para el dicho ofiçio Garçía de Auila, su padre, lo qual todo tiene en graçia nuestro sennor, vos aya en su santa guarda, de Segouia a quatro de nouiembre de cincuenta e ocho. Esto vos ruego mucho que fagays, paryentes e amigos por mi amor, el marqués". ${ }^{67}$

Podemos deducir por el contenido de esta carta, que el marqués había sido informado -seguramente por García Dávila o por su hijo, Gutierre de Padilla,- acerca de las leyes del concejo, que imposibilitaban a los miembros del cabildo acceder al oficio de mayordomo. Pero lejos de desistir en el empeño, Pacheco ideó un plan con el que, respetando en apariencia la normativa concejil, consiguió que García Dávila disfrutase de la mayordomía del concejo: el marqués solicitó el oficio para Gutierre de Padilla, vecino pechero de Jerez que al no encontrarse en el concejo para desempeñar la mayordomía, la ejercería a través de su padre, García Dávila. Pero a pesar de la intervención directa de Pacheco, la tenaz resistencia ofrecida por otros regidores como Iñigo López de Carrizosa, -fiel seguidor del duque de Medina-, obligó al marqués a remitir una nueva misiva al concejo insistiendo en su propósito:

"A mis buenos parientes e amigos, vuestra carta resçebí con Pedro de Vera, regidor e oy lo que me dixo de vuestra parte çerca de lo que toca al ofiçio del mayordomadgo desta çibdad y sea verdad conmo sabeys que yo vos auía e he escripto algunas veses rogando e pidiendo de graçia que por contenplaçion mía quesyesedes que Padilla, mi criado, fuese proueydo del ofiçio este presente anno, esto por el ser conmo es, natural desa çibdad e porque es mío e me ha seruido e syrue mucho e tengo del grand cargo por mí por esto creays que nin entençión nin voluntad fue en cosa alguna de yr contra vuestros preuillejos e usos e constunbres, nin de dar cabsa que ellos fuesen en poco nin mucho perjudicados, antes con verdad podeys creer trabajaría conmo siempre he fecho en las otras cosas de esta çibdad e procuraría que ellos fuesen guardados e tenidos en su fuerça e vigor, agora pues, asy es visto lo que desydes, non sabría al que vos desis çerca desto, saluo que lo remito a vosotros para que en ello fagays e deys aquella orden que entendieredes que mejor sea, syn enbargo de cosa alguna conmo quiera que ya la cosa ha llegado a tal estado e el terçio del anno es pasado en que la mas renta del dicho ofiçio me disen que se auia de auer a graçia, resçebiré mucho sy este anno le es dado al dicho Padilla porque sólo se conosca que por ser mío e me seruyr, sy le fase esa graçia, esto sy faser se puede en manera que esa çibdad non lo aya por mucho agrauio sobre lo qual todo mas largo el dicho Pedro de Vera vos fablará

${ }^{67}$ A.M.J.F., A.C., 1459, fol. 3r 
de mi parte, sea creydo por mi amor, nuestro sennor vos aya en su santa guarda, de Segouia a seys de abril de çinquenta e nueve, el marques, por mandado del marqués, mi sennor, Alfonso de Badajos ". ${ }^{68}$

Finalmente, tanto Juan Pacheco como García Dávila, consiguieron su objetivo, y el regidor jerezano acabó ejerciendo el oficio de mayordomo, eso sí, de manera compartida con otro vecino, Diego Díaz de Galdames. ${ }^{69}$

Otro de los grandes personajes jerezanos que entró en la órbita del marqués, aunque de manera indirecta, fue Pedro Fernández de Vera, que ejercía el oficio de jurado del concejo hasta que en 1458 accedió a la regiduría, obteniendo además merced real para traspasar la juradería a su hermano, Francisco de Vera. Además, llevaba acostamiento del maestre de Calatrava ${ }^{70}$ hecho éste que le supuso la expulsión de la ciudad en octubre de 1464 por orden del monarca. ${ }^{71}$ El regidor mostraba de manera evidente su simpatía personal hacia su sennor, además de su apoyo incondicional a la causa defendida por éste y por Pacheco, en el enfrentamiento con Enrique IV en 1465. ${ }^{72}$

Sin duda, las relaciones establecidas por los Vera con el marqués y con el maestre de Calatrava, beneficiaron la posición de esta familia dentro del concejo y también de su cabildo ${ }^{73}$ Pero en esto, también tuvo que ver el hecho de que en este linaje se daba una característica generalizada en la aristocracia jerezana: la heterogeneidad partidista de los miembros de una misma familia. Es decir, podemos observar cómo dentro de un mismo linaje, existían individuos que tomaban partido por un bando nobiliario, mientras que otros, lo hacían por el opuesto. Así, si hemos visto cómo Pedro Fernández de Vera pertenecía al círculo de Pacheco a través de su relación con Pedro

68 A.M.J.F., A.C. 1459, fol. 47r

69 Fueron aceptados ambos el miércoles 10 de mayo de 1459, A.M.J.F., A.C. 1459, fol. 48v. Sirve este ejemplo para mostrar, una vez más, la fuerza y personalidad del concejo jerezano, que aceptaba a García Dávila únicamente si compartía el oficio con un vecino pechero de la ciudad, Diego Díaz de Galdames.

70 A.M.J.F., A.C. 1466, fol. 2v, Pedro de Vera llama al maestre de Calatrava "su sennor". Véase también la nota $\mathrm{n}^{\circ} 41$.

71 A.M.J.F., A.C., 1464, fol. 191r.

72 La pertenencia al bando alfonsi de este personaje se ratifica, entre otros momentos, cuando tienen lugar las negociaciones para la adhesión de Jerez a dicho partido. La mayor parte del concejo mantenía sus reticencias a aceptar al infante, si bien, "solo un voto hubo y que llanamente y sin protesta dijo que había tenido y tenía por su rey al infante don Alonso, éste fue Pedro de Vera, primo del de Jimena, en quien esta ciudad siempre tuvo sospecha que seguía este partido", RALLÓN, Fray Esteban, op.cit., p. 318; esta misma posición queda reflejada cuando, tras la presentación en el cabildo de unos capítulos para que Jerez reconociese como rey a don Alfonso, Pedro de Vera indica que él, ya con anterioridad, había emitido su voto y que “... aquello era y es...", en el sentido de que siempre había estado de parte del infante, A.M.J.F., A.C. 1466, fol. 4v

73 En 1467, cuando ya el marqués había sido cesado al frente del corregimiento, podemos ver cómo Pedro Fernández de Vera llegó a ejercer la alcaldía mayor del concejo, consiguiendo que ante sus numerosas ausencias al cabildo, pudiese ejercer como su lugarteniente su hermano, el jurado Francisco de Vera: "Luego, los dichos Pero Núñes e Yñigo Lopes, alcaldes mayores entrega las varas de las dichas alcaldías al dicho Pero Marino por sy la una e a Françisco de Vera, jurado en nonbre del dicho Pedro de Vera, veynte e quatro, su hermano, la otra por que asy estana acordado por la çibdad e por virtud del poder que al dicho Françisco de Vera fue otorgada por el dicho Pedro de Vera, su hermano”, A.M.J.F., A.C. 1457 , fol. $17 \mathrm{r}$ 
Girón, otro miembro del mismo linaje, también llamado Pedro de Vera -posiblemente primo del anterior-, disfrutaba de la juradería de San Dionisio y de la alcaidía de la villa de Jimena, gracias a los vínculos que había establecido con don Beltrán de la Cueva, como sabemos, antagonista de Pacheco. ${ }^{74}$

Tras haber destacado la importancia que para Pacheco tuvieron tanto García Dávila como Pedro Fernández de Vera, no podemos olvidar al personaje jerezano que, seguramente, fue el seguidor más fiel del marqués en el concejo. Nos referimos a Agustín de Spínola, quien a pesar de no desempeñar ningún cargo u oficio en el cabildo, consiguió convertirse en un importante activo de la oligarquía jerezana gracias a su personalidad y a su relación con el marqués. El cronista Bartolomé Gutiérrez resume la personalidad de este auténtico diplomático que supo ganarse la aprobación de la monarquía y de la alta nobleza: “...gran fidelidad y maña para estar bien con los dos reyes, y con los confederados de uno y otro partido, mereciendo de todos las notadas mercedes y otras más, que no es fácil referir, en rentas que las asignaron de maravedis, trigos, y privilegios...". ${ }^{75}$ Siguiendo la narración de Gutiérrez, sabemos que fue juez de alzada del Tribunal de Suplicación y además “...caballero del Orden de Santiago, Comendador del Almendralejo, del Consejo de los Señores Reyes D. Enrique IV, y D. Alonso, Chanciller Mayor de la Orden de Santiago, Alcalde de los Alcázares de Estepona y su fortaleza, guarda y Vasallo de los Reyes...", sin olvidar que, gracias a su relación con Pacheco, fue alcaide de la villa de Estepona y recibió un oficio de regidor en Jerez de la Frontera, aunque éste no llegó a ejercerlo por la oposición del cabildo. ${ }^{76}$ De igual manera, desde 1457 desempeñó su labor como juez de términos junto a Antón Rodríguez, maestresala y vecino de Sevilla. Además, el carácter diplomático de Spínola, así como las excelentes relaciones que había establecido con altos dignatarios castellanos, predisponían su nombramiento como procurador del concejo ante la corte en numerosos e importantes casos. ${ }^{77}$

74 En la carta real que otorgaba el oficio de jurado de la collación de San Dionisio a Pedro de Vera, el monarca aludía a que dicha merced la realizaba a petición del propio Beltrán de la Cueva. Tampoco creemos que fuese coincidencia que dicha carta se mostrara en el cabildo del viernes 28 de septiembre de 1464, justo dos días antes de que se presentase la misiva por la que el monarca suspendía el corregimiento de Juan Pacheco, A.M.J.F., A.C. 1464, fols. 140v-141r. Beltrán de la Cueva, que era el señor de Jimena, delegó su guarda a los jerezanos Esteban de Villacreces y posteriormente a Pedro de Vera, pretendiendo crear una clientela afín en la comarca. Es de suponer que también don Beltrán estableciese relaciones con importantes nobles jerezanos, pues en gran medida, la manutención de la villa de Jimena dependía de Jerez, concejo al que el monarca había encomendado su protección: "En 1464, antes de ser nombrado maestre de la Orden de Santiago y duque de Alburquerque, Enrique IV mandaba al recaudador del partido de Jerez pagar a don Beltrán de la Cueva, para satisfacer los sueldos de las tropas que tenía en Jimena -120 hombres de a caballo y 230 de a pie-, 31.333 maravedis, importe de los 700 cahices de trigo...y 600 cahíces de cebada..., que servían de sostenimiento para esa guarnición", CARCELLER CERVIÑ̃O, M.P., en Realidad y representación de la nobleza castellana del siglo XV. El linaje de la Cueva y la casa ducal de Alburquerque, Madrid, 2006. Tesis doctoral dirigida por Elisa GARCÍA y M ${ }^{\text {a }}$ Concepción QUINTANILLA RASO, p. 144.

${ }^{75}$ GUTIÉRREZ, B., op.cit., pp. 104-105

${ }^{76}$ Ibídem, pp. 87-88

${ }^{77}$ Una de las comisiones más importantes de las que formó parte, fue la constituida junto al regidor Pedro Díaz de Villacreces, para negociar la guarda de Estepona que el concejo jerezano ejercía por mandato regio desde 1460 y que analizaremos en un apartado posterior, A.M.J.F., A.C. 1460, fols. 48r-v. Resulta interesante comprobar cómo otro de los grandes beneficiados por Juan Pacheco, el regidor Pedro 
La presencia de Agustín de Spínola en el concejo se hizo más frecuente desde que en 1456 fue nombrado alcaide de Estepona. Sus comparecencias ante el cabildo perseguían, generalmente, la obtención de recursos, avituallamientos y auxilio militar del concejo xericiense para la villa que custodiaba. En este sentido, hemos de señalar que la designación de Spínola como alcaide le reportó, además, la obtención de dos privilegios concedidos por el monarca: protección jurídica especial y exención de pechos e seruiçios en Jerez, ciudad de la que era vecino. El primero de los privilegios queda evidenciado en la narración de Bartolomé Gutiérrez, que da cuenta de una misiva real por la que se otorgaba al alcaide de Estepona inmunidad jurídica, ordenándose la desestimación de cualquier proceso, querella o requerimiento civil o criminal dado contra Spínola. ${ }^{78}$ En cuanto a la exención de pechos e seruiçios en el concejo jerezano, este privilegio queda constatado en la propia documentación capitular, comprobándose en diversas ocasiones cómo Agustín de Spínola se negaba a tributar o servir militarmente alegando que, como alcaide de Estepona, era franco y estaba exento de prestar seruiçios. ${ }^{79}$

Como ya hemos señalado, Spínola consiguió su nombramiento como regidor posiblemente en 1460, si bien, no pudo ejercer dicho oficio al no ser aceptado por el concejo. Para la concesión de la regiduría, el monarca debió tener en cuenta los méritos acuñados por Spínola, pero también debió pesar en esta decisión la intervención a su favor del marqués de Villena, quien tenía un especial interés en que su aliado accediese al regimiento jerezano. Efectivamente, Pacheco respaldaba a Spínola, pero no sólo por corresponder la fidelidad que éste le profesaba, sino porque si conseguía que fuese aceptado como regidor, habría logrado introducir en el cabildo a un personaje afín y fiel a su persona, aumentando así su influencia y control sobre el concejo. Tanto es así que, Juan Pacheco, habiendo sido cesado ya como corregidor de Jerez, continuó empeñado en que Spínola fuese recibido como regidor. A pesar de su insistencia, la respuesta del concejo jerezano fue siempre negativa. ${ }^{80}$

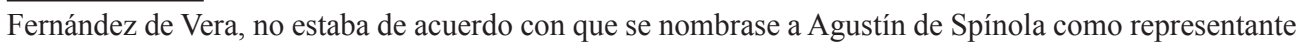
del cabildo: “...e el dicho Pedro Fernández de Vera, regidor, dixo que era en mengua del cabildo desta çibdad que onde auia regidores e jurados que non que no deuía ir mandadero de fuera del cabildo e eso mesmo dixo el dicho Ynigo Lópes...”. ¿Puede que el ascenso que experimentaba Agustín de Spínola no fuese bien visto por otros caballeros jerezanos que tenían las mismas aspiraciones y al mismo protector?, o por el contrario, ¿quizás simplemente se trataba de una formalidad institucional?

78 GUTIERREZ, B., op.cit., pp. 13-15. Carta fechada en Madrid el 15 de diciembre de 1457.

79 “...veno miçer Agostín de Spínola, alcayde de la villa de Estepona e dixo que el es franco e esento de non pechar e seruir por ser alcaide de la dicha villa, según la carta de merçed e franquisia que la dicha villa de Estepona tiene del rey nuestro sennor...", A.M.J.F., A.C. 1459, fol. 103r

${ }^{80}$ En 1467, el concejo jerezano se vio forzado a reconocer a don Alfonso como legítimo rey, con la resistencia de algunos regidores jerezanos, que por esta oposición fueron suspendido en sus oficios, quedando vacantes sus regidurías -concretamente se habla de dos-. Esto fue aprovechado por uno de los grandes señores de la región, el duque don Juan de Guzmán, quien solicitó al nuevo rey don Alfonso y al propio marqués de Villena, una de estas regidurías para su criado, Diego de Ávila, que además era hijo del regidor jerezano García Dávila. Su petición fue atendida y aceptada, pero Juan Pacheco, que no iba a perder su oportunidad, le impuso una condición: que para la otra vacante fuese reconocido Agustín de Spínola, que ya tenía la merced otorgada desde 1460 pero que no había sido aceptado por el cabildo. "...E el dicho sennor duque le prometio al dicho sennor marqués que el dicho miçer Agostín sería resçebido al dicho ofiçio asy conmo el dicho Diego de Áuila y que non se resçebiría al uno syn el otro...", A.M.J.F., A.C. 1467, fols. 38v-39v. Independientemente de intereses particulares y partidistas, 


\section{EL FINAL DEL CORREGIMIENTO DE JUAN PACHECO EN EL CONCEJO JEREZANO Y EL DESVANECIMIENTO DE SU INFLUENCIA EN LA REGIÓN}

Aunque como veremos, la conclusión del corregimiento de Juan Pacheco tuvo lugar de manera definitiva en 1465, no podemos pasar por alto un hecho narrado por Esteban Rallón, según el cuál, sólo tres años después de la concesión del corregimiento al marqués, éste se planteó la posibilidad de dejar dicho oficio a cambio de una compensación. Para Rallón, la propuesta partió de los hermanos Francisco y Pedro de Vera, quienes se encontraban en la corte para tratar el ya mencionado caso del asesinato del alcalde mayor Juan García de Castro. Según el cronista, aprovecharon su audiencia con el marqués para proponerle, a título personal y sin autorización del concejo, el final del corregimiento. La compensación solicitada por Pacheco habría sido de 170.000 maravedíes, más la promesa de Jerez de hacerse cargo del mantenimiento de Estepona. Los delegados jerezanos sólo habrían ofrecido 80.000 maravedíes, algo que habría sido desestimado por el marqués. Pero, finalmente, "tratose el negocio con varias pretensiones de una parte a otra, y en fin los obligó a que hiciesen una escritura, en virtud de la creencia de la ciudad, en que la obligaron a pagarle cien mil maravedies, quedando para la ciudad el derecho del bizcocho y de las semillas, los oficios de la justicia y alcaldías, menos el de alguacil mayor y que la ciudad cuidase de Estepona, con ciertas condiciones..." ${ }^{81}$ Es decir, que tras ser rechazadas por ambas partes la oferta y la contraoferta, según Esteban Rallón, hubo un pacto por el que el marqués, a cambio de dejar el corregimiento, conseguía que Jerez se hiciese cargo del mantenimiento de Estepona, que le fuese concedido el alguacilazgo del concejo, y finalmente, que se le abonase la nada desdeñable cantidad de 100.000 maravedíes. Este acuerdo, si existió, revela tres aspectos fundamentales: por un lado, que las expectativas que Pacheco tenía puestas en el proyecto corregimiento de Jerez - tenencia de Estepona, no estaba dando sus frutos; por otro, que el marqués no estaba dispuesto a renunciar al control del concejo jerezano, ya que se reservaba el alguacilazgo mayor de la ciudad; y en cuanto al tema de Estepona, dejándola al cuidado de Jerez, Pacheco pudo haber encontrado una fórmula para que, descargándose del coste del mantenimiento de la villa, ésta fuese controlada por algún jerezano afín a su persona. Fuese como fuese, este posible acuerdo no se llevó a la práctica según podemos comprobar en las Actas Capitulares, siguiendo el marqués como titular del corregimiento y de la tenencia de Estepona.

Realmente, el final del corregimiento de Juan Pacheco, vino determinado por la suspensión del oficio por parte del monarca en septiembre de 1464, con motivo del deterioro de las relaciones entre ambos. ${ }^{82} \mathrm{Si}$ bien, la definitiva revocación no llegó

el rechazo del cabildo a aceptar tanto a Spínola como a Diego de Ávila, radica en que éstos accedían al cargo en sustitución de otros dos que no habían sido cesados en su oficio, sino solamente suspendidos, por lo que en el momento en que retomaran su oficio se volvería a acrecentar el número de regidores, tendencia propia del siglo XV pero contra la que los oficiales jerezanos protestaron durante esta centuria en más de una ocasión, a la par que fomentaban según conveniencias particulares.

81 RALLÓN, Fray Esteban, op.cit., pp. 266-267

82 La carta de la suspensión del oficio se leyó en el cabildo extraordinario del domingo 30 de septiembre de 1464, ejerciendo por entonces el corregimiento, en nombre del marqués, Gonzalo Dávila, 
hasta 1465, cuando el marqués, que apoyaba al infante don Alfonso, estaba abiertamente enfrentado a Enrique IV. ${ }^{83}$

El cese del corregimiento, sumado a la mayor presión que en estos momentos ejercían en la región el duque de Medina Sidonia y el conde de Arcos, complicaba la influencia de Pacheco en Jerez y, por extensión, en Andalucía. Sin embargo, ante esta complicada situación, el marqués no desistió en su empeño y realizó un cambio de estrategia, urdiendo un nuevo plan con dos objetivos prioritarios: uno de ellos consistía en retomar el poder y la influencia sobre la corona castellana, algo que resultaba ya imposible con Enrique IV, muy entregado a D. Beltrán de la Cueva. Por tanto, Pacheco tenía que encontrar a alguien que pudiese ser coronado rey y fuese fácilmente manejable y, ¿quién mejor que el infante don Alfonso? Dada la corta edad del nuevo monarca, éste quedaría supeditado al marqués, que se encargaría de supervisar y controlar todos los asuntos importantes en la corte. El segundo de los objetivos iba encaminado a conseguir la adhesión a la causa alfonsí del mayor número posible de señores, villas y ciudades que, aceptando a don Alfonso, ingresaban indirectamente en el área de influencia de Pacheco, que era realmente el director de este proyecto. En este sentido, desde 1465, el concejo jerezano sufrió continuas presiones para que reconociese a don Alfonso como legítimo rey, a la par que recibía de Enrique IV numerosas prebendas y privilegios, pretendiendo prolongar la fidelidad que la ciudad le profesaba. Entre otros, concedió a la ciudad el título de Muy Noble y Muy Leal Ciudad de Jerez de la Frontera, el privilegio de la veinticuatría -acrecentando el número de regidores de 13 a 24- y el privilegio de Tarifa, por el que los oficios de regidores y jurados se hacían hereditarios. ${ }^{84}$ Pero a pesar de todo, el concejo acabó por reconocer al infante en 1466, lo que significó de nuevo la entrada, aunque de manera indirecta, en la órbita del marqués de Villena. Si bien, la influencia de Pacheco sobre Jerez había quedado difuminada, entre otras razones, por el empuje ejercido en la región por el duque de Medina Sidonia y el conde de Arcos.

En cuanto a la red clientelar creada por Juan Pacheco, tras su cese como corregidor, parece como si ésta hubiese desaparecido por completo. Tanto es así que, cuando el monarca en 1464 ordenó la expulsión de Jerez del corregidor y de todos los seguidores del bando alfonsí, las autoridades jerezanas sólo hallaron a dos personas sospechosas de pertenecer al partido liderado por Pacheco. ${ }^{85} \mathrm{Y}$ aunque el principal factor causante de la disolución de la red clientelar del marqués en el concejo jere-

\footnotetext{
A.M.J.F., A.C., 1464, fols. 145r y ss.

83 “...se abrió una carta del rey que por su mano enviaba a Xerez, de la confirmación de los privilegios y revocación de la merced que habia hecho a don Juan Pacheco del corregimiento de Xerez...", RALLÓN, Fray Esteban, op.cit., p.305. Este autor afirma que la presentación de la carta en el cabildo tuvo lugar el lunes 2 de diciembre de 1465; para Bartolomé GUTIÉRREZ, la revocación definitiva del oficio la realizó el monarca el 19 de julio, en op.cit., p. 58.

${ }^{84}$ RALLÓN, Fray Esteban, op.cit., pp. 304-306; estos hechos también son narrados por Bartolomé GUTIÉRREZ, op.cit., pp. 55-87.

${ }^{85}$ Como personajes sospechosos de pertenecer al partido liderado por Pacheco, se nombra a un vecino de Jerez llamado Diego García Ferrador y al regidor Pedro Fernández de Vera, que vivía con Pedro Girón, A.M.J.F., A.C., 1464, fol. 191r; asimismo circulaba información referente a la presencia en la ciudad de otro sospechoso de pertenecer a la órbita del marqués, el lugarteniente del Almirante, Juan Barba o Juan Bautista (según se consulte uno u otro cronista), quien expulsado de Sevilla estaba viviendo en Jerez, GUIÉRREZ, B., op.cit., p. 54 y RALLÓN, Fray Esteban, op.cit. p. 296.
} 
zano fue su propio cese como corregidor, no podemos olvidar que existieron otros aspectos que han de valorarse a la hora de explicar este hecho. Por un lado, tenemos que tener en cuenta que, aunque algunos de sus seguidores mantuvieron su fidelidad -como fue el caso de Spínola-, no debieron ser pocos los nobles jerezanos partidarios de Pacheco que acabaron por encomendarse a otros señores: si Pacheco no podía proporcionarles protección, privilegios y mercedes, buscarían a un nuevo patrocinador. Por otro lado, también debemos considerar el hecho de que un gran número de regidores y jurados jerezanos llevaban acostamiento directo del propio Enrique IV, de quien habían recibido numerosas mercedes y gratificaciones a lo largo de su reinado. El monarca, mediante ésta estrategia, consiguió crear y mantener una especial lealtad hacia su persona, y ante la tesitura de tener que elegir entre Pacheco o el monarca, la gran mayoría optaría por apoyar a éste último. Tampoco debemos ignorar la influencia que en la zona había comenzado a tener el propio Beltrán de la Cueva a través de la tenencia de Jimena y de Gibraltar. El control de estas plazas lo ejerció mediante lugartenientes seleccionados de entre la nobleza jerezana, con lo que además, ganó adeptos en el concejo. En este sentido, es más que probable que don Beltrán estableciese nuevas relaciones en la zona cuando, a principios de 1464 y esta vez sin Pacheco, realizó una visita junto al monarca Enrique IV a tierras andaluzas, siendo acompañado durante varios días por cincuenta de los mejores caballeros jerezanos. ${ }^{86}$ Finalmente, otro de los motivos que difuminaron el clientelismo de Pacheco en Jerez fue la constatada pervivencia de relaciones cercanas, e incluso de parentesco, entre la oligarquía jerezana y miembros de la casa de Guzmán y de la de los Ponce de León.

A pesar de que tras el cese como corregidor había comenzado el final de la influencia de Pacheco en el concejo jerezano, el marqués no renunció a sus pretensiones e intentó mantener partidarios en el consistorio xericiense. Un buen ejemplo, ya comentado, es el apoyo que prestó a Agustín de Spínola, su fiel partidario, para que éste pudiera ejercer el oficio de regidor en el cabildo. Otro ejemplo nos lo proporcionan las concesiones realizadas por Pacheco al jerezano Pedro Díaz de Villacreces, quien recibió 25.000 maravedís de juro de heredad sobre las rentas de paños y frutas de Jerez, como contraprestación personal a un servicio armado que realizó como capitán de las huestes jerezanas a favor de don Alfonso en 1467. ${ }^{87}$ Pero como decimos, estos últimos intentos resultaron infructuosos.

\section{LA TENENCIA DE ESTEPONA: ELEMENTO CONSUSTANCIAL AL CORREGIMIENTO JEREZANO}

La decidida estrategia llevada a cabo por el marqués de Villena para neutralizar a todo aquel que intentaba superarlo en influencia y autoridad, explica en gran medida la conflictividad politica vivida en Castilla en la segunda mitad del siglo XV. Como arma para combatir el posible ascenso de terceros, nada mejor que incidir en la expansión política y territorial de su poder, algo que explica perfectamente su intento de asentarse en Andalucía, estableciendo dos de sus bases en Jerez y Estepona, enclave

86 GUTIÉRREZ, B., op.cit., pp. 48-51.

87 RALLÓN, Fray Esteban, op.cit., p. 340 
éste que será controlado por el marqués desde su conquista. La tenencia de la villa malagueña no suponía para el marqués el simple control de un puesto fronterizo con el reino nazarí, sino un elemento clave dentro de un proyecto más ambicioso, perfectamente calculado y en el que entraban en juego otras piezas estratégicas. Se puede afirmar que era concebido como un primer intento por parte de Pacheco y con él, del monarca castellano, de avanzar en la conquista del territorio granadino. En este sentido, destacamos la opinión de Ana Echevarría Arsuaga, quien afirma que durante este período, Enrique IV desarrolló una política militar activa contra Granada, pero adaptada a las capacidades y posibilidades del momento, basándose en la tala y el sabotaje de los recursos granadinos y el cobro de parias como método bélico, lejos de la pusilanimidad atribuida al monarca, en este sentido, por cronistas como Alonso de Palencia. ${ }^{88}$ Así pues, ¿estaba Estepona destinada a ser el punto de partida de un nuevo señorío de Pacheco en Andalucía? ¿Pensó en ella como una primera base territorial desde la que emprender la adquisición de nuevos territorios?

La toma de Estepona y su concesión a Juan Pacheco, tienen su origen en las campañas militares que Enrique IV, acompañado del marqués, llevó a cabo contra Granada en 1456. En este contexto, posiblemente el 12 de mayo, fue tomada la plaza tras haber sido abandonada días atrás por los musulmanes. Ahora se planteaba un nuevo problema, ¿quien querría hacerse cargo de una villa despoblada, que requería reparaciones y estaba mal defendida por su situación geográfica y por su cercanía a tierras enemigas? Evidentemente, la persona que mostrase interés por una villa en las condiciones descritas, debía tener un propósito más allá de la mera posesión de una plaza fronteriza. Este perfil encajaba perfectamente con el del marqués de Villena que fue quien solicitó la tenencia de Estepona, en teoría, para guardarla de los posibles ataques de los infieles y para mayor honra del monarca y de la patria cristiana. ${ }^{89}$ Tratándose de Pacheco, es lógico pensar que la adquisición de un compromiso como éste, llevaba consigo una contrapartida: si tomamos como ciertas las palabras de fray Esteban Rallón, es posible que Pacheco, para poder conservar y defender la villa de Estepona, negociara con el monarca la concesión del corregimiento perpetuo de Je-

${ }^{88}$ Ana ECHEVARRÍAARSUAGA profundiza en este sentido, señalando que "se ha insistido mucho en rebajar la categoría de las campañas de Enrique IV contra Granada emprendidas al comienzo de su reinado, principalmente a causa de la excesiva dependencia de los historiadores respecto a la crónica de Alonso de Palencia". Esta autora afirma que, tras un correcto cotejo de las distintas fuentes de la época, queda evidenciado que “...esta ofensiva ocupó un lugar fundamental en la definición de la figura del rey en términos propagandísticos y políticos". Concluye indicando que "es difícil saber si la iniciativa partió del propio rey, o del marqués de Villena y su círculo, pero en cualquier caso tenía como fin el fortalecimiento de la posición del rey e indirectamente, del marqués...", en "Enrique IV de Castilla, un rey cruzado", Espacio, Tiempo y Forma, serie III, Historia Medieval, t. 17, 2004, pp. 2-3

89 "otro día el rey mandó asentar su real cerca de Marbella, donde fizo tala en los panes y el dia siguiente se asentó e real cerca de Marbella, donde fizo tala en los panes y el día siguiente se asentó el real cerca de la villa de Estepona, y el rey se aposentó dentro della, en la qual ninguna cosa se falló. $Y$ el marqués de Villena suplicó al rey que le fiziese merced de aquella villa, y al rey plugo dello, y mandola bastecer de los mantenimientos que en la hueste avía y las armas, las que eran menester para su defensa", en VALERA, Diego de, op.cit., p. 34. Alonso de Palencia dice de Estepona, que era una plaza interesante para la guerra contra Granada, pero que "el llano en que está asentada ofrecía tan poca seguridad contra los asaltos que los moros temían, que no podía dejar de ser tomada", en op. cit., libro V, cap. IV, p.107. 
rez de la Frontera, pero no sólo por lo que económicamente representaba, sino por la fuente de poder que dicho oficio le otorgaba en la zona. ${ }^{90}$ En definitiva, ¿fue la tenencia de Estepona el pretexto empleado por el marqués para conseguir el corregimiento jerezano?

Jerez, como sabemos, era en esa época la punta de lanza occidental en la guerra contra Granada, tanto para la contención de las embestidas nazaríes como para el avance cristiano sobre territorio granadino. Pacheco, conocedor de esta realidad, sabía que el control del concejo le proporcionaría una garantía de auxilio desde la retaguardia en caso de un, más que probable, ataque musulmán a la villa de Estepona. De hecho, no son pocos los ejemplos que al respecto encontramos en las fuentes jerezanas. Uno de ellos lo hallamos en la sesión del cabildo del miércoles 14 de junio de 1459, en la que un vecino de Estepona se presentó ante los capitulares jerezanos para informarles de la inminente llegada de un ejército granadino a la villa, rogando "... que por seruiçio de Dios e del rey nuestro sennor, esta çibdad parta luego en socorro de la dicha villa...". El concejo jerezano, curtido en la lucha fronteriza, determinó que caualleros y peones de la ciudad se apresurasen a estar "...prestos e aparejados para salir e yr con el pendón de esta çibdad sopena de perdimiento de sus ofiçios e bienes para la camara del rey e de las otras penas ordenadas por Xeres...". ${ }^{91}$

Para que se realizara con éxito el repoblamiento de Estepona, el 16 de junio de 1456, el monarca otorgó un albalá que, además de franquicias fiscales, concedía el perdón jurídico a todo aquel que habiendo incurrido en delito, fuese a morar a la villa por un tiempo no inferior a diez meses..$^{92}$ Además, se intentó garantizar cierta seguridad a la villa mediante el establecimiento de paces con la cercana Gibraltar, importante enclave islámico en la región desde el que se gestaban muchas de las embestidas musulmanas. En las Actas Capitulares jerezanas se conserva el traslado de la misiva que el monarca castellano remitió al concejo xericiense días después de la toma de Estepona y en la que instaba al cumplimiento de las treguas firmadas con

${ }_{90}$ El historiador advierte que para administrar satisfactoriamente la villa de Estepona, el monarca concedió al marqués el alguacilazgo de Sevilla -algo de lo que no tenemos noticia- y el corregimiento jerezano: “...y uno y lo otro fue para que mas fácilmente pudiera conservar la villa de Estepona, que también se la había dado", op. cit., p.260. Es posible que Rallón, cuando se refiere al alguacilazgo, lo confunde con la alcaldía mayor de Sevilla, oficio éste que sí le fue concedido al marqués (véase nota $n^{\circ}$ 39).

91 A.M.J.F., A.C. 1459, fol. 74 r; al estudiar la documentación capitular comprobamos otros muchos ejemplos en este sentido, como la solicitud realizada por la villa de Estepona al concejo jerezano de 20 ballesteros para el mantenimiento militar de la plaza, en A.M.J.F., A.C. 1457, fol. 16v; pero Jerez también asistía a Estepona en labores logísticas como el envío a dicha villa de bestias para las recuas del abastecimiento, así como de 100 caballeros para velar por la seguridad de dicha caravana, en A.M.J.F., A.C. 1457 , fol. 56r.

92 Las Actas Capitulares del cabildo del martes 25 de octubre de 1457, albergan un traslado de este albalá, aunque la data del mismo corresponde al 20 de junio de 1456 . Entre sus cláusulas, se establecía que "...todos los ommes e mugeres de cualquier estado o condiçión que sean, que a la dicha villa de Estepona fueren poblar e morar o en ella estouieren por sus presonas e a su costa e misión continuadamente por tyempo de dies meses conplidos mostrandolo por ffe del alcayde de la dicha villa e de un alcalde e de dos regidores della firmadade sus nombres e signada de escriuano público, que sean quitos e perdonados e yo por la presente les perdono cualesquier muerte o muertes de omme o de ommes o muger o mugeres e omesillos e tomas e robos que ayan fecho e fisieren en que ayan caydo e cayeren en cualquier manera o por cualquier rasón que sea...", A.M.J.F., A.C. 1457, fols. 85v y ss. 
la villa gibraltareña: "Conçejo, justiçia, regidores, caualleros, escuderos ofiçiales e omes buenos de la noble çibdad de Xeres de la Frontera, yo he tomado en mi guarda e so mi seguro e amparo e defendimiento real al alcaide e aljama e omes buenos, vesinos e moradores de la villa e fortaleza de Gibraltar, por ende yo vos mando que les non fagades nin consintades faser guerra ni mal ni danno por mar ni por tierra en sus presonas ni en sus bienes ni en cosa alguna de lo suyo, mas que los guardedes e anparedes en manera que non reçiban ningund danno...". ${ }^{93}$ No es de extrañar que esta iniciativa partiese del propio Juan Pacheco, interesado en mantener protegidos sus intereses en la zona.

Con Estepona como punto de partida, el marqués intentaría ampliar sus posesiones y establecer un señorío propio en Andalucía, basándose en la adquisición de nuevas tierras provenientes de la guerra contra Granada. Pero para reclamar y administrar esos nuevos dominios había que estar en primera línea de batalla, llegar el primero, en definitiva. Quizás, una primera oportunidad para ello se presentó en la conflictiva toma de Gibraltar, que tuvo lugar en 1462 y en la que Jerez, comandada por el corregidor Gonzalo Dávila -lugarteniente de Pacheco-, participó junto a otros concejos y señores de la zona, entre los que se encontraba don Rodrigo Ponce de León, hijo del conde de Arcos, quien lideraba la contienda en representación de su padre y a la espera de la llegada del duque de Medina Sidonia. ${ }^{94}$ El asedio a Gibraltar por parte de las tropas cristianas obligó a la villa gibraltareña a presentar su rendición. Pero ésta fue rechazada momentáneamente por Rodrigo Ponce de León quien, conocedor de la inminente llegada del duque de Medina Sidonia, prefirió esperarle para tratar juntos este asunto. La respuesta negativa de Rodrigo a la capitulación, provocó una inesperada reacción del corregidor Gonzalo Dávila, quien realizó un pacto encubierto con los principales de la villa gibraltareña, garantizándoles el cumplimiento de los términos de la entrega, a cambio de que se permitiese la entrada en la villa a las huestes jerezanas que él lideraba. Gibraltar, temiendo una toma violenta por parte de las milicias cristianas, aceptó la propuesta del corregidor jerezano. Así lo narraba Diego de Valera: "Y con esta respuesta los moros se boluieron muy tristes a la ciudad. Y como don Rodrigo se volvió por el camino del real, los caballeros de Xerez no fueron con él, antes se boluieron a la ciudad; y Gonçalo de Ávila habló con Mahomad Caba, diziéndole que bien avía entendido aquellas palabras que don Rodrigo le avía dicho, el qual era caballero que se andaua a ganar honrra. Y que viniendo el conde fuese cierto que combatirían la ciudad y la tomarían por fuerça, y serían catibos ellos y mujeres; y que el remedio desto era que le diesen aquella puerta y las otras de allá, y quél y los caballeros que alli estauan la defenderían, y meterían dos mill hombres que alli tenía de Xerez, y él cumpliría con ellos todos lo que avían demandado. Y con

${ }_{93}$ Este fragmento pertenece al traslado de una carta emitida desde Tarifa el 27 de mayo de 1456, A.M.J.F., A.C. 1456, fol. 39v. En esta misma línea se siguió actuando en años posteriores, como por ejemplo en 1459, cuando el 20 de noviembre, el alcaide de Estepona, Agustín de Spínola, acudió al cabildo jerezano para procurar su adhesión a las treguas que se habían establecido por tres meses con Gibraltar y a la que ya se habían sumado otras villas y señores de la zona como el conde de Arcos y el duque de Medina Sidonia, A.M.J.F., A.C. 1459, 103r

94 “....y otro dia siguiente llegó alli el pendón de Xerez, con quatrocientos de cauallo y muchos peones, e Gonçalo de Ávila con él, que hera buen cauallero y tenía el corregimiento de aquella çiudad...", VALERA, D., op.cit., p.76 
esta fabla los moros fueron tan atemorizados, que no les quedó esfuerço ni razón, e abrieron luego las puertas." Pero el intento resultó fallido, ya que los hombres de Rodrigo se percataron de este hecho y lo aprovecharon para entrar en la villa por la fuerza. ${ }^{95}$ Aun así, la toma de Gibraltar evidenció la rivalidad entre Ponces y Guzmanes, pues ambos bandos mantuvieron una fuerte pugna por ver a quién correspondía la ocupación de la fortaleza, saliendo victorioso de este enfrentamiento Juan Alonso Pérez de Guzmán, duque de Medina Sidonia. Pero el éxito del duque duraría poco, pues el monarca se apresuró a reclamar la villa para incorporarla a la Corona castellana.

Esteban Rallón, que también narra este suceso, afirma que Gonzalo Dávila se decidió “... sólo con su gente á tomar la plaza por el Rey”. Pero, ¿sería esa la verdadera voluntad del corregidor? La información de que disponemos sólo nos permite especular sobre las intenciones de Dávila, pero podemos intuir, dada la personalidad de Pacheco, que si la toma de Gibraltar se hubiese producido de forma satisfactoria y en exclusividad por García Dávila, quizás el marqués hubiese reclamado la tenencia de la villa para él o para algún personaje afín. Esta posibilidad debió ser vislumbrada por el propio duque de Medina Sidonia cuando el monarca requirió la entrega de Gibraltar para incorporarla a la Corona. Tanto es así que el duque, para ceder la villa gibraltareña exigió al rey que jurase que "...no la enagenaría jamás de la corona", ${ }^{96}$ pretendiendo con ello que Gibraltar no cayese en manos de otros señores rivales en la región, pero tampoco en las del marqués de Villena, quien ya había iniciado su establecimiento y expansión en la zona.

Pero a pesar de la importancia que Juan Pacheco había otorgado a Estepona dentro de su proyecto en Andalucía, pronto comenzó a percatarse de que la tenencia de la villa no sólo no estaba proporcionando los frutos previstos, sino que además estaba resultando especialmente costosa. Si la villa debía ser la base desde la que expandir sus posesiones, ¿de qué servía su tenencia si el avance sobre tierras nazaríes apenas superaba las escaramuzas fronterizas? Por ello, a principios de 1460 el marqués devolvió la plaza al monarca quien, hasta no encontrar a una persona válida y suficiente para su cuidado, encargó su guarda al concejo de Jerez. ${ }^{97}$ Es incluso probable que fuese el propio Pacheco quien recomendara al monarca que Estepona quedase bajo la protección del concejo xericiense, pretendiendo con ello que la villa fuese custodiada por algún jerezano cercano a su persona. De hecho, uno de los candidatos que se barajó en el cabildo para la guarda de Estepona, el regidor Pedro de Vera, estuvo apoyado en este asunto por el también regidor y paniaguado del maestre de Calatrava, Pedro Fernández de Vera. Si bien, finalmente resultó elegido Bartolomé Núñez de Villavicencio, regidor y personaje afín al duque de Medina Sidonia.

95 Ibídem, p. 78. Según se consulte a uno u otro cronista, la narración de la toma de Gibraltar presenta ciertas variantes.

96 PALENCIA, Alonso de, op.cit., libro VI, cap.VI, p.138

${ }^{97}$ La noticia se anunció en el cabildo del 3 de marzo de 1460; puede seguirse este caso en A.M.J.F., A.C.1460 fols. 15r-19r. RALLÓN sostiene que la causa de su devolución fue que la villa "...estaba muy apartada, era más de coste que provecho y estorbaba a sus intentos el tiempo que en ella gastaba", op.cit., p. 272 
El elevado coste que conllevaba el mantenimiento de Estepona también se deduce de las diversas quejas realizadas por Bartolomé Núñez, para quien los 80.000 maravedís bimensuales concedidos por el monarca para tal efecto, resultaban insuficientes. Por ello, el concejo jerezano creó una comisión para tratar el asunto directamente con el monarca con el objetivo de conseguir, al menos, una compensación en caso de que la ciudad tuviese que hacerse cargo de la villa de manera definitiva. Pero la solución que el monarca encontró a este problema fue tajante, sorprendiendo al propio cabildo jerezano: se ordenó que Estepona fuese demolida. ${ }^{98}$ Lo más probable es que para tomar una determinación sobre este asunto, el monarca se dejase aconsejar por el que había sido "alcaide" de Estepona, quien no dudaría en proponer su demolición para garantizarse de que ningún otro competidor pudiese triunfar en su tenencia y recibirla como merced.

Aún así, Pacheco no tenía la más mínima intención de perder las rentas y prebendas que la tenencia de Estepona le proporcionaba. Por ello, una vez se deshizo de la villa malagueña, solicitó al monarca la concesión de Xiquena, enclave situado en la frontera nororiental granadina, con lo que, por una parte, no perdía los cuantiosos estipendios que percibía por Estepona y por otra, mantenía la posesión de una plaza limítrofe con el reino nazarí, más cercana a sus dominios en el marquesado de Villena y que igualmente podría servirle de plataforma para una posible extensión de sus territorios e influencia en Andalucía. ${ }^{99}$

\section{CONCLUSIÓN}

El corregimiento de Juan Pacheco en Jerez de la Frontera, ha de ser enmarcado en el contexto de las ambiciosas aspiraciones del marqués en Andalucía, para quien el control del concejo jerezano suponía un pilar básico en sus pretensiones de expansión y afianzamiento en la región. Para conseguir su propósito contó entre sus principales bazas con el corregimiento jerezano, la tenencia de Estepona, el apoyo de su hermano Pedro Girón y la posesión de una alcaldía mayor en Sevilla. ${ }^{100}$ Asimismo, el marqués, en su intento por lograr sus objetivos, manipuló el enfrentamiento existente entre la casa de Niebla y la de Arcos, favoreciendo a ésta última con la intención de debilitar la posición del duque de Medina Sidonia, principal enemigo del marqués de Villena en la región. ${ }^{101}$

\footnotetext{
${ }^{98}$ A.M.J.F., A.C. 1460, fols. 34r-v.

99 Edward COOPER considera que el hecho de hacerse con una plaza en la frontera jienense facilitaría "... al marqués los cimientos para realizar una ambición a largo plazo: La Reconquista del mismo reino de Granada. A partir de 1456 son sistemáticos sus esfuerzos para reunir los demás recursos necesarios para llevarlo a cabo", en Castillos señoriales en la Corona de Castilla, Vol. 1, Salamanca, 1991, p. 95. Para Alonso de Palencia, Juan Pacheco, lo que pretendía era apropiarse de gran parte de las cantidades percibidas para el mantenimiento de Xiquena ya que, en opinión del cronista, la villa era una “...posición que cuatro hombres podrían defender seguramente...", op.cit., libro V, cap. IV, p. 107.

100 Véase la nota ${ }^{0} 39$

101 Isabel MONTES ROMERO-CAMACHO señala que el marqués de Villena, observó en el hijo del conde de Arcos, Rodrigo Ponce de León, un buen elemento de confrontación contra el duque, por lo que Pacheco "...fomentó la guerra entre ambos", en "Un gran concejo andaluz ante la guerra de 
Pero todo el proyecto se vio perjudicado por el cambio de la coyuntura política, que le llevó irremediablemente a emprender una nueva estrategia de la que no obtuvo los frutos pretendidos: la desaparición del infante don Alfonso y la imposibilidad de liquidar el arraigo y las sólidas clientelas formadas por las casas de Niebla y de Arcos en Andalucía, fueron dos de las causas fundamentales que clausuraron el proyecto político y la influencia del marqués en la región.

Granada: Sevilla en tiempos de Enrique IV (1454-1474)”, En la España Medieval, nº, 1984, p. 602. La tensión entre el duque de Medina Sidonia y el marqués de Villena queda también evidenciada en el relato de Alonso de Palencia, quien indica que, “...el Duque por su parte, personaje principal entre la nobleza andaluza y el primero en Sevilla, aborrecía a D. Juan Pacheco, no por sus demás ventajas, sino porque, igual suyo, no quería que le reputasen inferior los sevillanos", op. cit., libro IV, cap. I, p. 82. 